\title{
وعي سكان منطقة تبوك بحقوق الأشخاص ذوي الإعاقة
}

\author{
هدى فضل الله علي محمد

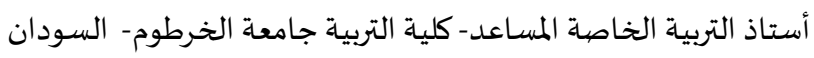 \\ Ahuda735@yahoo.com \\ نجوى سليمان مسلم المسعودي \\ معلمة تربية خاصة بمنطقة تبوك- السعودية
}

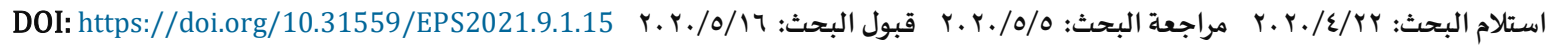

تهدف الدراسة الحالية إلى دراسة مدى وعي سكان منطقة تبوك بحقوق الأشخاص ذوي الإعاقة. تكونت عينة الدراسة من (ro I ا)

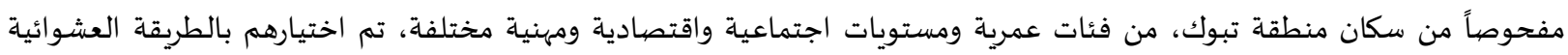

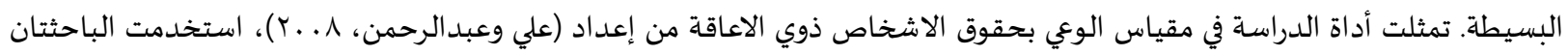

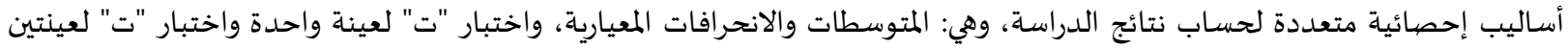

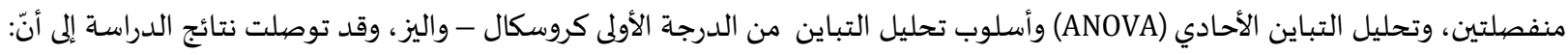

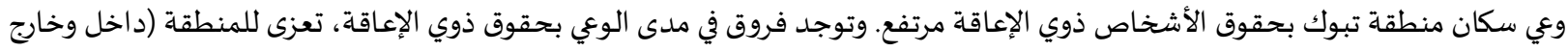

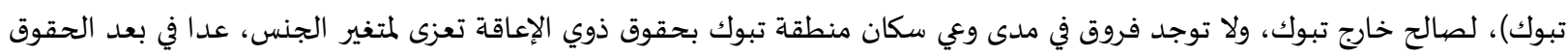

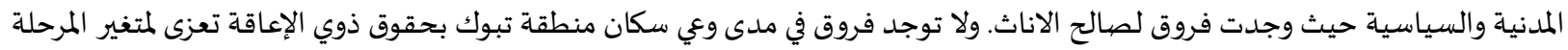

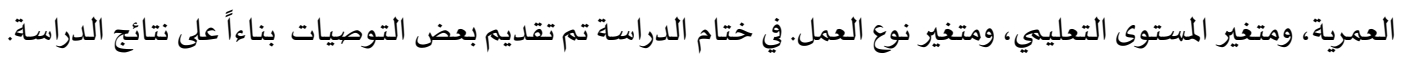
الكلمات المفتاحية: ذوي الإعاقة؛ الوعي بحقوق ذوي الإعاقة؛ اتفاقية حقوق الأشخاص ذوي الإعاقة.

شغلت قضية حقوق الانسان حيزاً كبيراً عبر الحضارات المتواترة لدى مختلف المفكرين من خلال النظريات الفلسفية والسياسية، وتعاليم

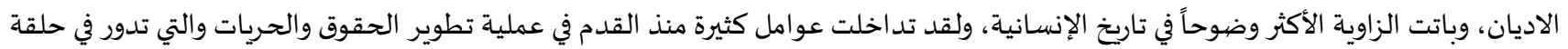

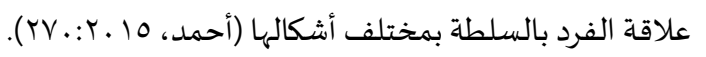

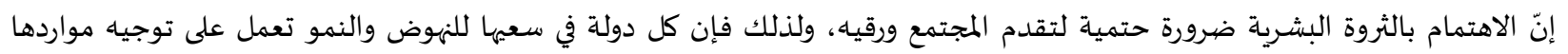

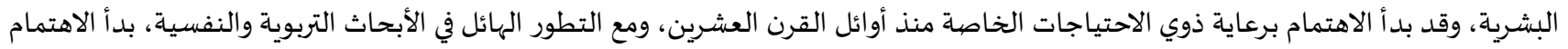

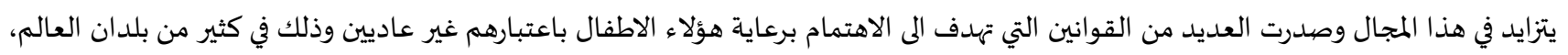

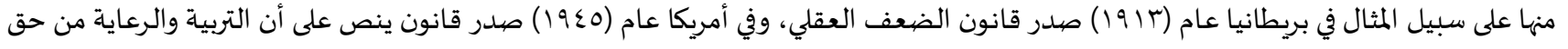

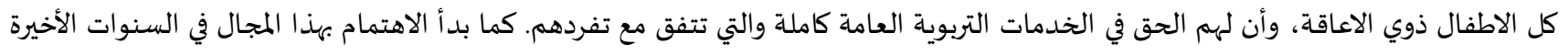

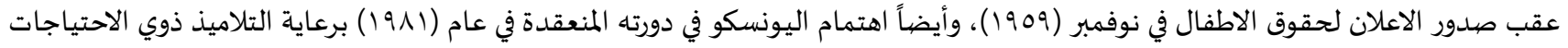


أشار تقرير حديث صادر عن منظمة الصحة العالمية (World Health Orgnization,2011) الى أنّ ذسبة انتشار الإعاقة اصبحت أعلى بكثير مما

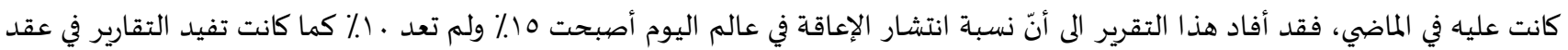
السبعينات من القرن الماضي وهو العقد الذي أجريت فيه آخر دراسة مسحية للإعاقة على مستوى العالم، ويعني ذلك أنّ عدد الأشخاص المعوقين في

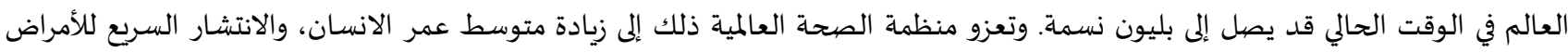

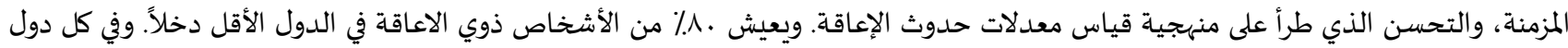

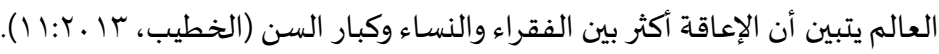

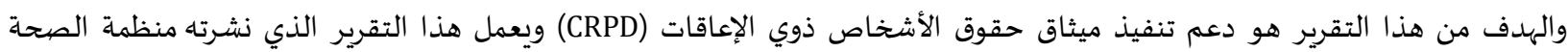

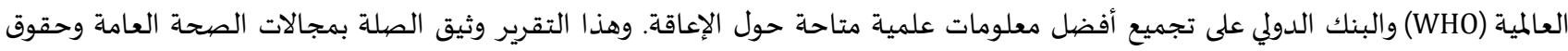

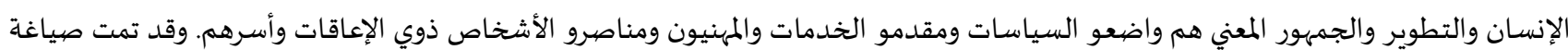
هذا التقرير بمشاركة كاملة من الأشخاص ذوي الإعاقات والمؤسسات المسؤولة عنهم، وكذلك أصحاب مصالح معاتح معنيون آخرون، وقد جاء في التقرير ايضياً أن:

أكثر من مليار شخص في العالم لديهم شكل ما من أشكال الإعاقة. وهذا يمثل قرابة 0 1\% من سكان العالم. وهناك عدد يتراوح ما بين (11 (11 -

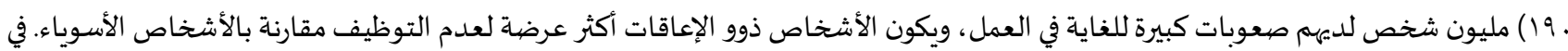
دول منظمة التعاون الاقتصادي والتنمية يرتفع متوسط توظيف الأشخاص ذوي الإعاقات (عء٪) قليلاً عن نصف متوسط توظيف الأشخاص من غير

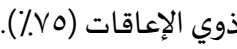

غالبًا لا يحصل الأشخاص ذور الإعاقات على الرعاية الصحية اللازمة. نصف الأشخاص ذوي الاعاقة لا يمكنهم توفير تكاليف الرعاية الصحية، مقارنةً بثلث الأشخاص من غير ذوي الاعاقة. الأشخاص ذوو الإعاقات تزيد لديهم احتمالية اكتشاف عدم كفاية الإعاية مهارات موفري الرعاية الصحية أكثر

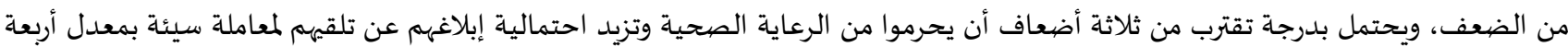
أضعاف مقارنة بالأشخاص الأسوياء. يكون الأطفال ذوي الإعاقات أقل احتمالية للذهاب للأداء للمدرسة مقارنةً بالأطفال من الأسوياء. توجد فجوات إكمال التعليم لدى جميع المجموعات

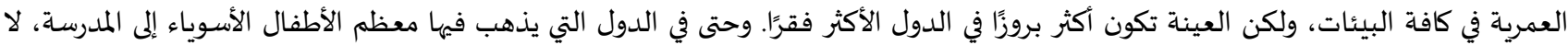

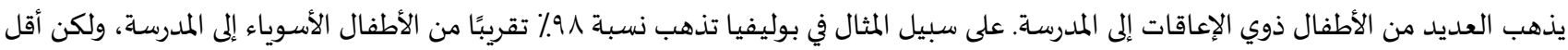

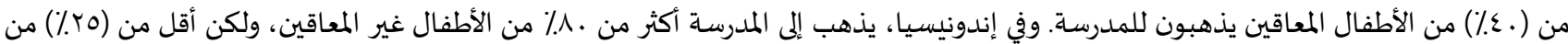

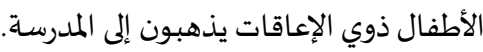

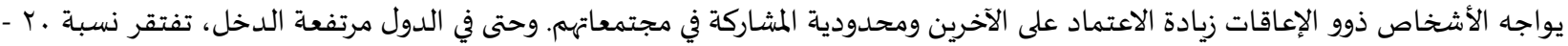

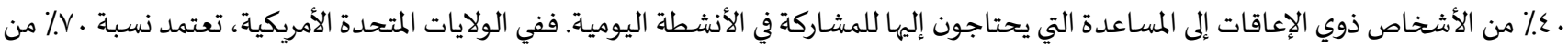
البالغين ذوي الإعاقات على الأسرة والأصدقاء للحصول داعلى على مساعدة في الأنشطة اليومية (World report on disability,2011).

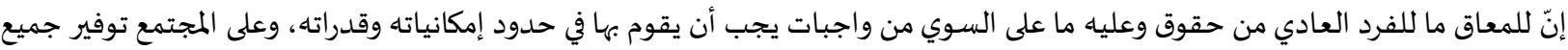

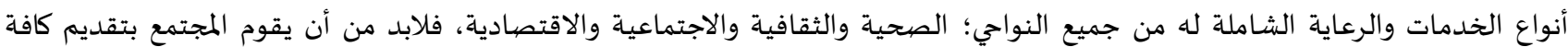

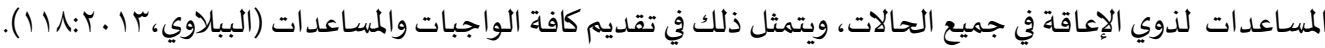

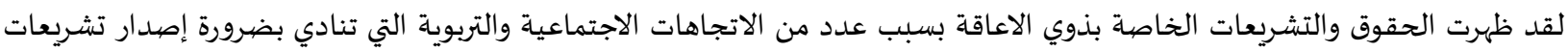

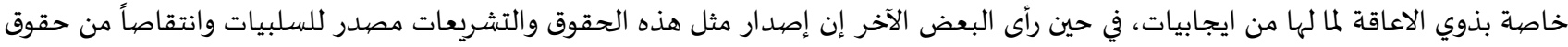

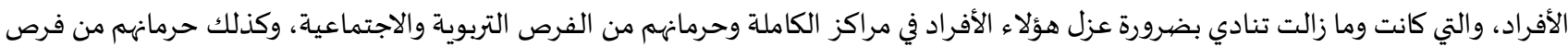

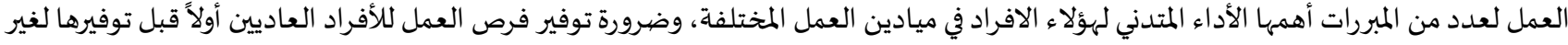

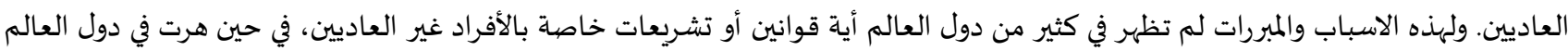
القوانين والتشريعات الخاصة بالأفراد غير العاديين، والتي تعكس مواقف الدول ذات المواقف الإيجابية من الأفراد غير العاديين، ولهذا كله اعتبرت

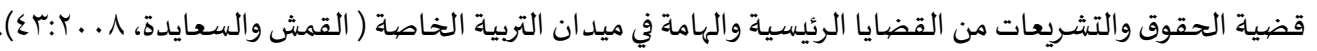

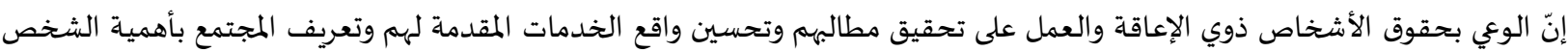

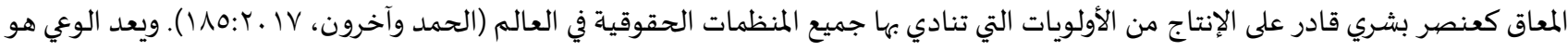

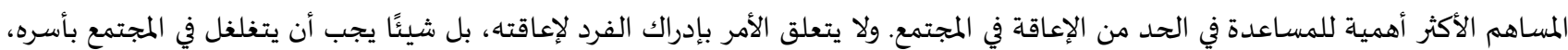
بحيث يخلق مواقف صحيحة تجاه الأشخاص ذوي الإعاقة. 
مشكلة الدراسة:

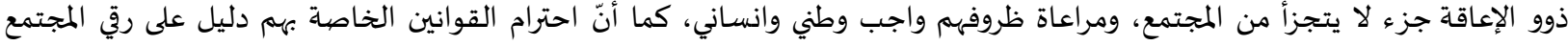

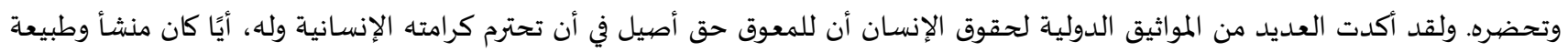

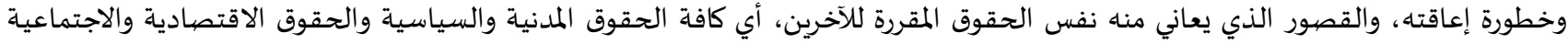

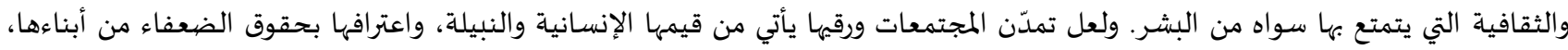

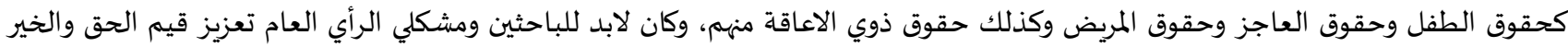

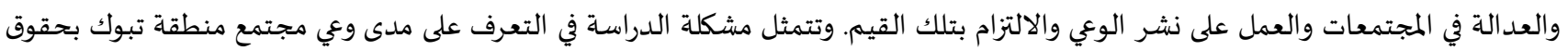

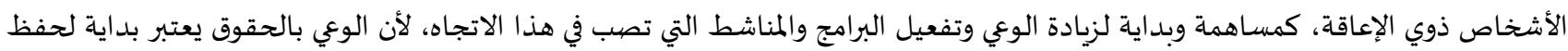

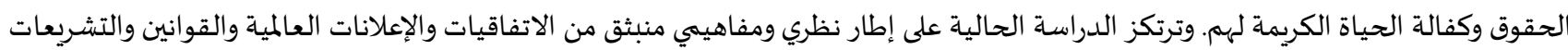
المحلية التي تناولت موضوع حقوق ذوي الاعاقة. وتتمثل مشكلة الدراسة الحالية في الإجابة عن التساؤلات الآلآية التية:

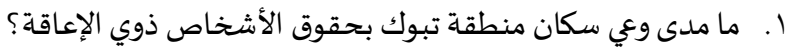

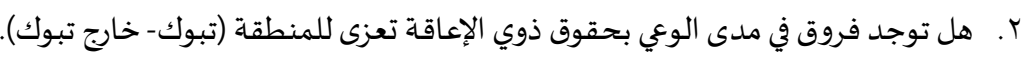

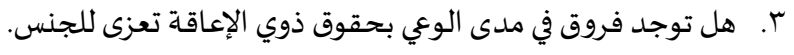

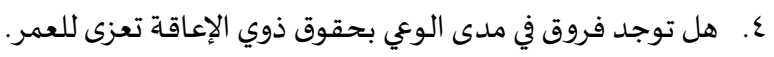

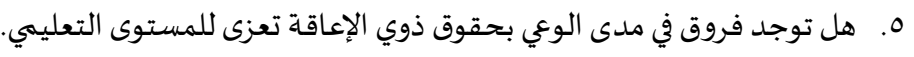
7. آ. هل توجد فروق في مدى الوعي بحقوق ذوي الإعاقة تعزى لنوع العمل.

أهمية الدراسة:

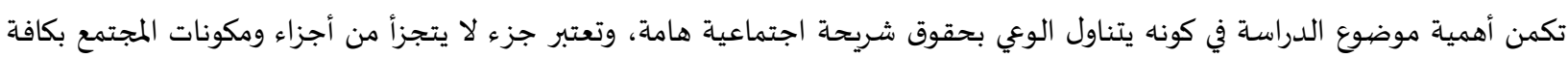

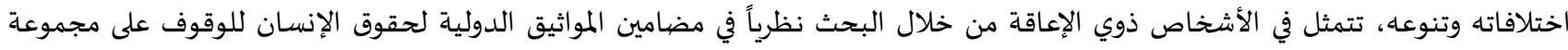

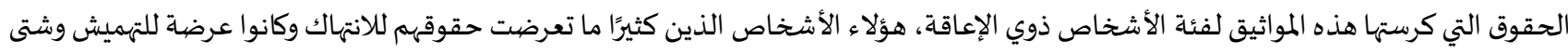
أنواع التمييز. كما تظهر أهمية الموضوع أيضًا بأها تتناول مدى وعي مجتمع منطقة تبوك بحقوق ذوي الإعاقة، لأن منطقة تبوك -في حدود علم الباحثتئين - لم

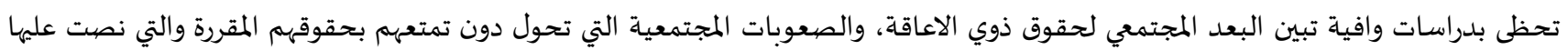
القوانين والدساتير الإنسانية وكذلك الشريعة الإسلامية.

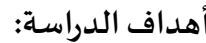

$$
\begin{aligned}
& \text { 1. إلقاء الضوء نظرياً على حقوق ذوي الإعاقة في التشريعات والأنظمة المحلية والدولية. }
\end{aligned}
$$

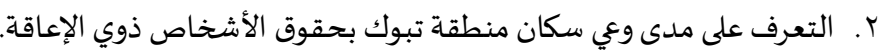

$$
\begin{aligned}
& \text { r. معرفة الفروق في مدى الوعي بحقوق ذوي الإعاقة تعزى للمنطقة (تبوك- خارج تبوك). }
\end{aligned}
$$

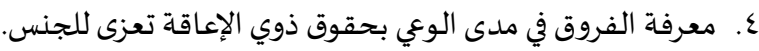

$$
\begin{aligned}
& \text { 0. معرفة الفروق في مدى الوعي بحقوق ذوي الإعاقة تعزى للعمر. }
\end{aligned}
$$

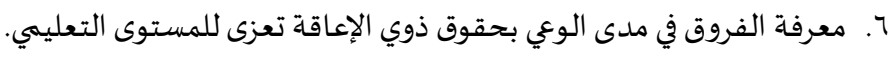

$$
\begin{aligned}
& \text { V. معرفة الفروق في مدى الوعي بحقوق ذوي الإعاقة تعزى لنوع العمل. }
\end{aligned}
$$

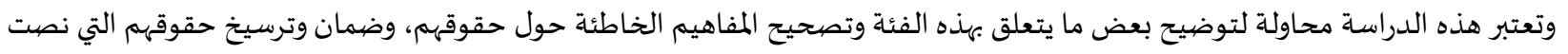

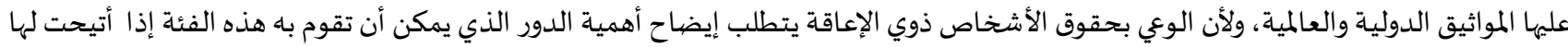

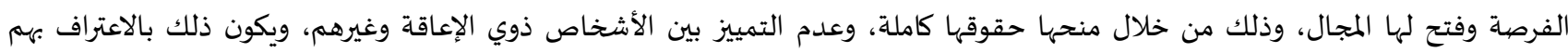
وبوجودهم وضرورة تمتعهم بالكرامة البشرية، والتاكيد على تقبل المجتمع واستيعابه لهم في كافة مناحي الحياة التعليمية والمهنية والمجتمعية كذلك. 
عدم قدرة الفرد على الاستجابة للبيئة أو التكيف معها نتيــة مشكلات سلوكية أو جسمية أو عقلية، والعجز هو الذي يسبب هذه المشكلات عند

تفاعل الفرد المصاب مع البيئة (القمش والسعايدة، م . . ب: . ب).

حقوق ذوي الإعاقة:

هو مصالح ثابتة للأفراد ذوي الإعاقة تقرره الاتفاقات الدولية والقوانين المعمول بها في المنطقة العربية والدول التي تعمل على حمايتها.

الوعي بحقوق ذوي الإعاقة:

مجموع المعلومات والمهارات والخبرات التي يتم إكسابها لأفراد المجتمع بشكل عام ولذوي العلاقة بموضهوع الإعاقة والمعوقين على وجه الخصوص

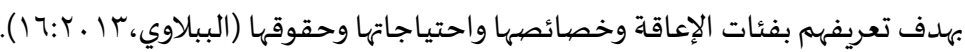

التعريف الإجر ائي للوعي بحقوق ذوي الإعاقة في هذه الدراسة:

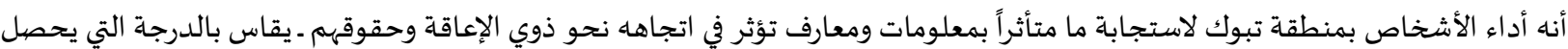

عليها الفرد في استجابتاه لمقياس الوعي بحقوق ذوي الإعاقة (أداة الدراسة).

الإطار النظري:

إنّ الطفل ذو الإعاقة هو طفل له وضعية خاصة واحتياجات خاصة بسبب الإعاقة التي ترهقه وتعرقله عن الاندماج السريع في المجتمع؛ ما يستوجب أن تكون له رعاية خاصة أيضاً، وقد التفتت اتفاقية حقوق الطفل لوضعية الأطفال المعوقين كونهم يستحقون العناية والرعاية والحماية

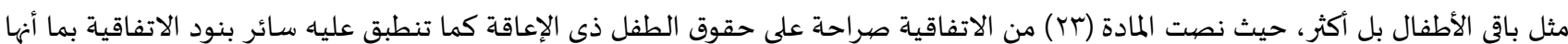
موجهة للطفل بصفة عامة. وقد نصت المادة (Yr) على ما ما يلي: تعترف الدول الأطراف بوجوب تمتع الطفل ذي الإعاقة الفكرية أو الجسدية بحياة كاملة وكريمة، في ظروف تكفل له كرامته وتعزز اعتماده على يلى النفس وتيسر مشاركتاه الفعلية في المجتمع تعترف الدول الأطراف بحق الطفل المعوق في التمتع برعاية خاصة تشجع وتكفل للطفل المؤهل لذلك وللمسؤولين عن رعايته رهناً بتوفير الموارد،

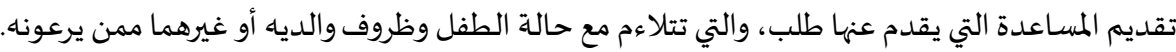

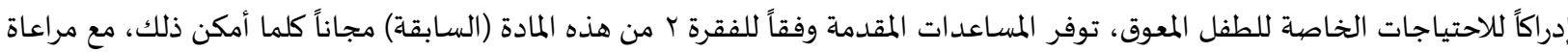

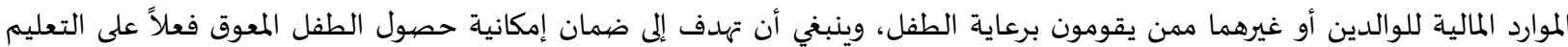
والتدريب، وخدمات الرعاية الصحية، وخدمات إعادة التأهيل، والإعداد لممارسة عمل. والفرص الترفيهية وتلقياء ذلك بصهورة تؤدي إلى تحقيق الاندماج الاجتماعي للطفل ونموه الفردي. بما في ذلك نموه الثقافي والروحي، على أكمل وجه ممكن. (http://boes.org/multiniguall). وعلى إلى الدول الأطراف أن تشجح، بروح التعاون الدولي، تبادل المعلومات المناسبة في ميدان الرعاية الصحية الوقائية والعلاج الطبي والنفسي والوظيفي للأطفال ذوي الإعاقة، بما في ذلك نشر المعلومات المتعلقة بمناهج إعادة التأهيل والخدمات المهنية وإمكانية الوصول إلهيها، وذلك بغية تمبلة تمكين الدول الأطراف من تحسين قدراتها ومهاراتها وتوسيع خبراتها في هذه المجالات. وتراعى بصفة خاصية، في هذا الصددد، احتياجات البلدان النامية

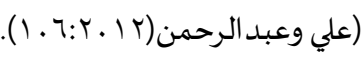

إنّ وجود تشريع لذوي الاعاقة يقوم على أساس من سيادة القانون الذي يعتبر ضرورياً لتأكيد حقوقهم، فيما يتعلق بجميع جوانب الحياة التي

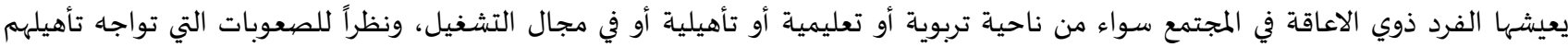
وتشغيلهم بشكل خاص، واتجاهاتهم واتجاهات أصحاب العمل وعدم وجود التشريعات التي تحمي حقوقهم، تتشكل معوقات أمام نجاح عمليات

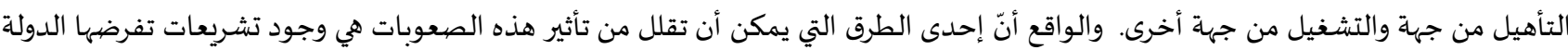

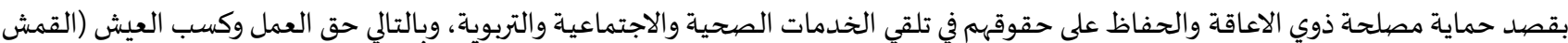

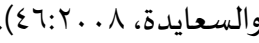

أنّ العناية بالأطفال ذوي الإعاقة كفئة أصابتها درجة من درجات داتهات العجز واجباً أخلاقيًا إنسانياً تفرضها القيم الدينية والأخلاقية والإنسانية

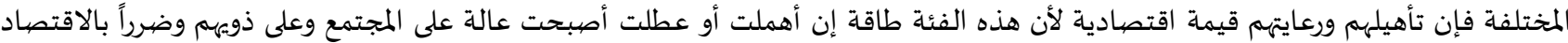
القومي فضلا عن أن العناية بهم لتجنب المجتمع أعباء كثيرة مستقبلاً. إن لكل فرد من الأفراد ذوي الإعاقة حقاً في الرعاية الصحية والتعليمية والتأهيلية في جميع مراحل نموه، وله حق العمل والتهل التوظيف في مرحلة

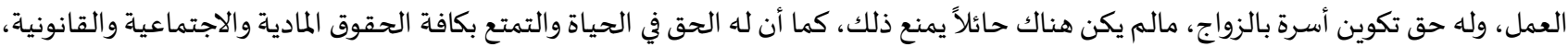
وعليه واجبات المواطنة بقدر الاستطاعة وتحمل المسئولية، وتجاهل هذه الحقوق أو إغفال يكلف المجتمع ثمنا باهظاً، فزيادة تدهور أحوال هذه الفئة 
يحولها إلى طاقات غير مستثمرة، ويصبحون عالة أو عبئا على ذويهم ومجتمعاتهم، ومما يعرضهه للانحراف الاجتماعي والأخلاقي؛ لذا يجب على المجتمع

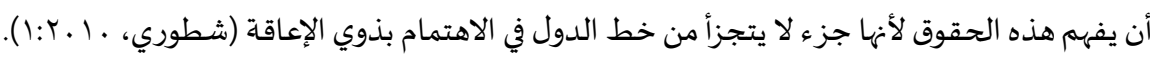
ومع تزايد أعداد الأطفال ذوي الإعاقة في العالم ومع تعقد المشكلات التي يعانون منها ومع زيادة احتياجاتهم الاجتماعية، والاقتصادية، والصحية،

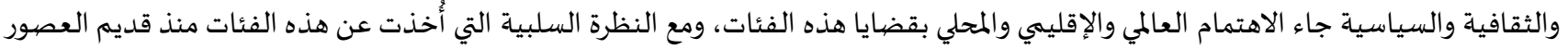

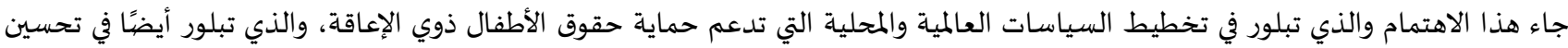
الخدمات والبرامج المتعلقة بالأشخاص ذوي الاحتياجات الخاصة وكذلك لكاء إصدار التشريعات والقوانين والإعلانات والاتفاقيات العالمية المختلفة التي

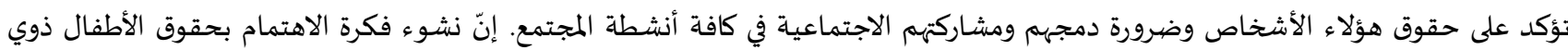

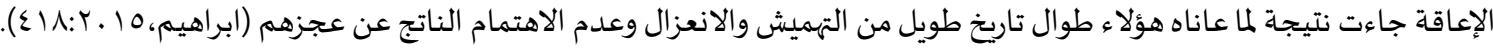

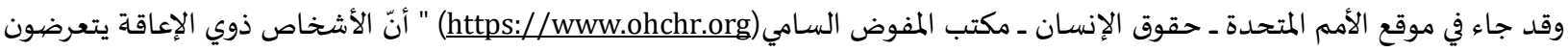
كل يوم للتمييز، والعوائق تقيد مشاركتهم في المجتمع على قدم المساواة مع غيرهم. وهم يُحرمون من حقوقهم في الاندماج في نظام التعليم العام، وفي

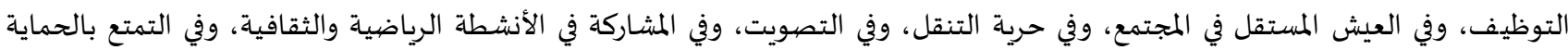
الاجتماعية، وفي الوصول إلى العدالة، وفي اختيار العلاج الطبي، وفي الدخول بحرية في التزامات قانونية مثل شراء وبيع الممتلكات. وفي الأعوام الأخيرة، حدث تغيير ثوري في النهج، على الصعيد العالمي، من أجل سد فجوة الحئ الحماية وضيمان تمتع الأشخاص ذوي الإعاقة بنفس معايير المساواة والحقوق والكرامة التي يتمتع بها جميع الأشخاص الآخرين"

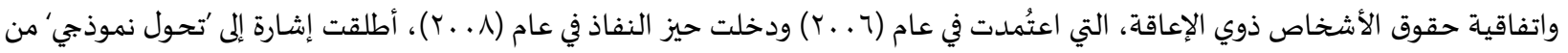

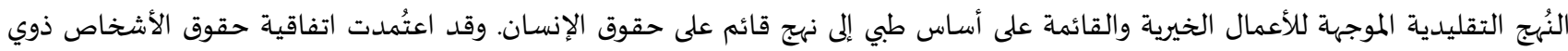

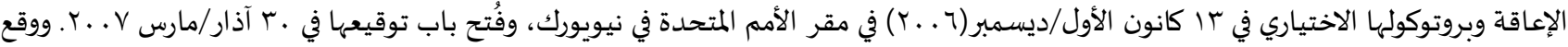

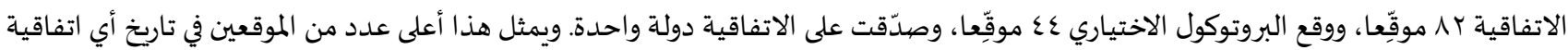

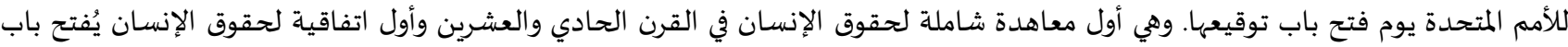

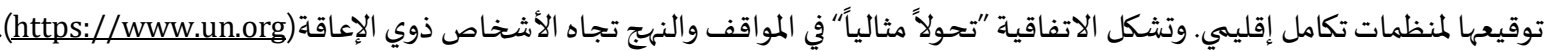

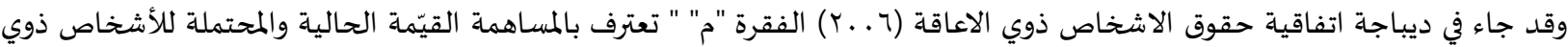

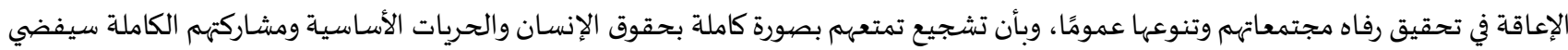

إلى زيادة الشعور بالانتماء وتحقيق تقدم كبير في التنمية البشرية والاجتماعية والاقتصادية للمجتمع والقضياء على الفقر" (بhttps://www.un.org).

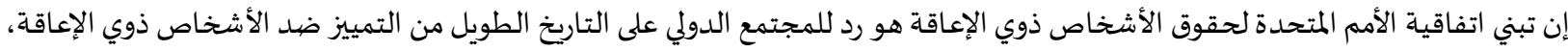

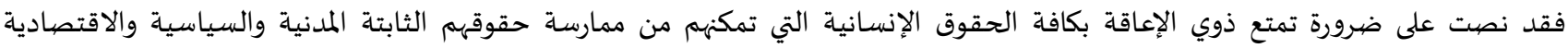

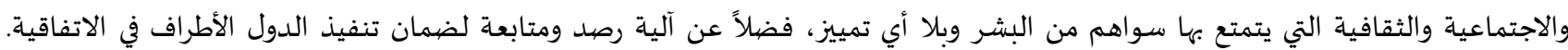

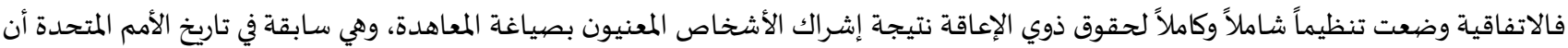

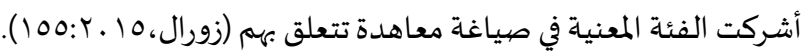

اتفاقية حقوق الأشخاص ذوي الإعاقة: تعتبر اتفاقية حقوق الأشخاص ذوي الإعاقة المعتمدة من قبل الأمم المتحدة(ه) الأداة الدولية الأولى الملزمة قانونياً، التي تعبر بالتفصيل عن

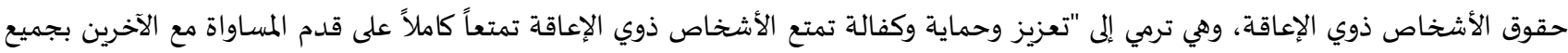

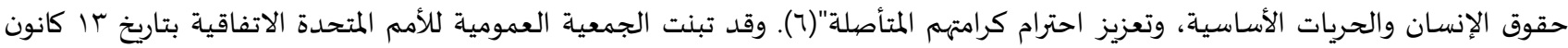

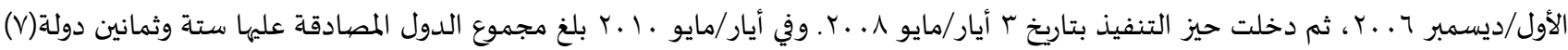

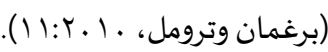
أشارت ديباجة الاتفاقية الى أنً الإعاقة تشكل مفهوماً لا يزال قيد التطور، وأهمية زيادة تكافؤ الفرص للأشخاص ذوي الإعاقة وما يتصل

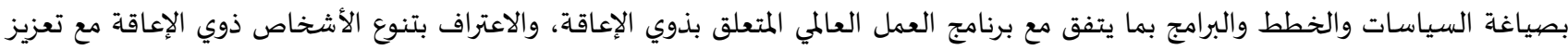

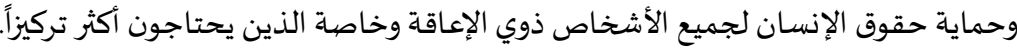

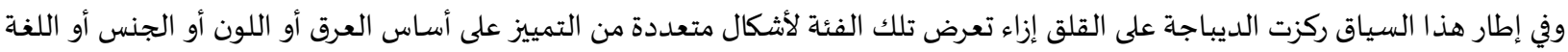
أو الديانة أو الرأي السياسي أو المولد أو السن ولذلك اعترفت بأهمية استقلالهم الذاتي وحرية تحديد خبراتهم بأنفسهم ومشاركتهم بفاعلية في عمليات اتخاذ القرارات بشأن السياسات والبرامج بما في ذلك تلك التي تعنيهم مباشرة. 
اعترفت الوثيقة بما يتعرض له النسـاء والفتيات ذوات الإعاقة من العنف أو الاعتداء وسوء المعاملة والاستخلال كما تعترف بضرورة تمتع الأطفال

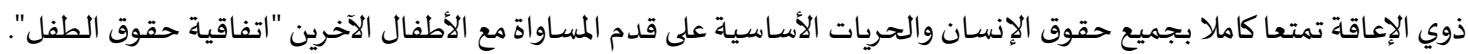
وأبرزت الوثيقة الحاجة الملحة لتخفيف ما للفقر من تأثير سلبي على الأشخاص ذوي الإعاقة، ووضعت في الاعتبار توفير الحماية الكاملة لهم ولا

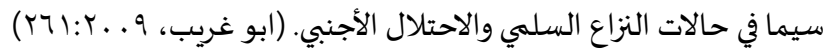

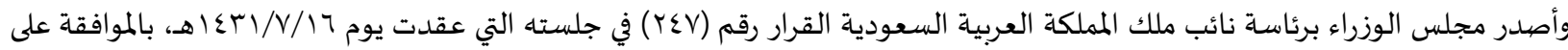
انضمام المملكة العربية السعودية إلى البروتوكول الاختياري لاتفاقية حقوق الطفل المتعلق ببيع الأطفال وبغاء الأطفال واستغلال الألطائل الألفال في المواد

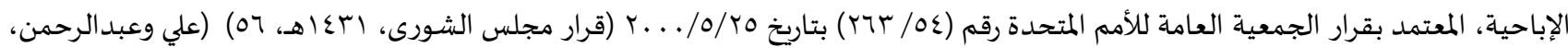

(1.N:T. IT

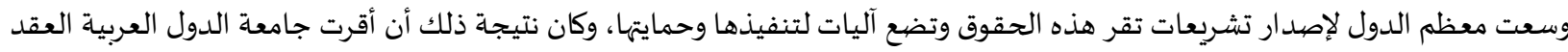

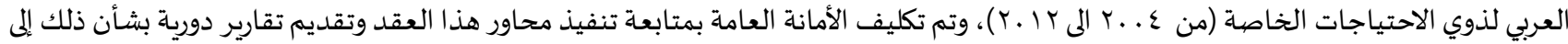

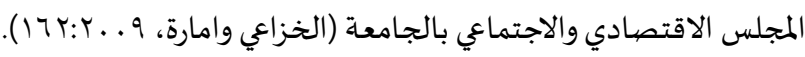
ويعتبر الوعي بحقوق ذوي الإعاقة هو الخطوة الأولى في تكوين الجوانب الوجدانية بما تتضمنه من الاتجاهات والقيم وعلى الرغم من وقوع الوعي

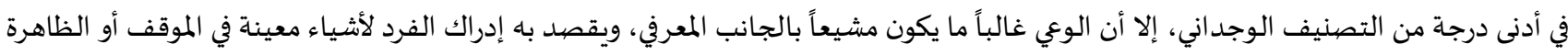
وله مجالات متعددة منها: الوعي البيئي والوعي الاجتماعي والسياسي والاقتصادي والتي يمكن تقويمها لدى الأفراد باستخدام مقاييس الوعي (شحاته

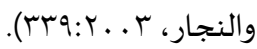

الدراسات السابقة:

هنالك عدة دراسات تناولت الوعي بحقوق ذوي الإعاقة منها:

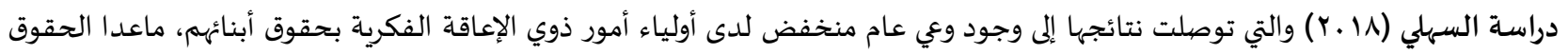

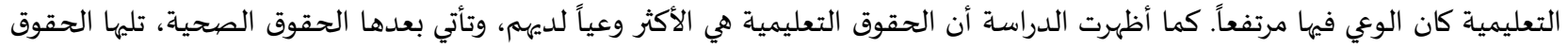

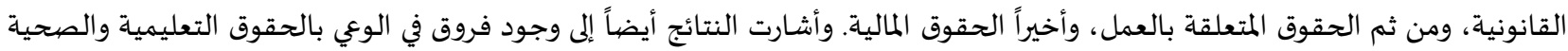
والدرجة الكلية للوعي بالحقوق, تعود لمتغير "الجنس"، لصالح الإناث. وكذلك وجود فروق في الوعي بالحقوق الصحية والمتعلقة بالعمل والدرجـة

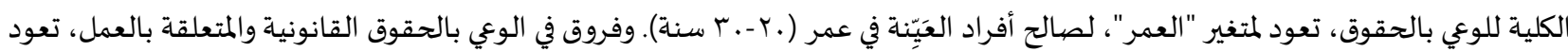
لمتغير "الدرجة العلمية"، لصالح أفراد العَيِّنة الحاصلين على (ابتدائي). كما أظهرت النتائج وجود فروق في الوعي بالحقوق الصحية، تعود لمتغير

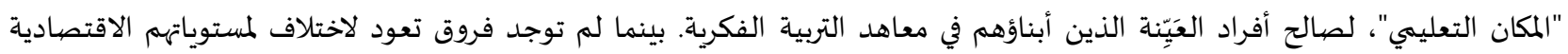
والاجتماعية. أما دراسـة الحمد والحسن، و الشرعة (Y (Y) والتي جاءت بهدف التعرف على مستوى الوعي بحقوق الأشخاص ذوي الإعاقة لدى طالبات كلية

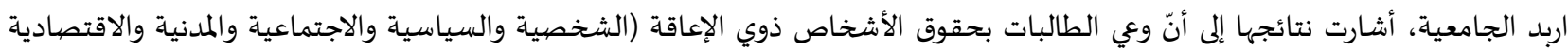
والتعليمية) جاءت بدرجة متوسطة، ولم توجد فروق في درجة وعي الطالبات بحقوق الأشخاص ذوي الإعاقة تعزى لمتغير التخصص الدراسي. ودراسـة (Rosli, 2017) والتي هدفت إلى دراسـة دور الاعلام في الوعي المجتمعي تجاه حقوق ذوي الاعاقة . تظهر النتائج أن مستوى الوعي العام حول الأشخاص ذوي الإعاقة إيجابي إلى حد ما.

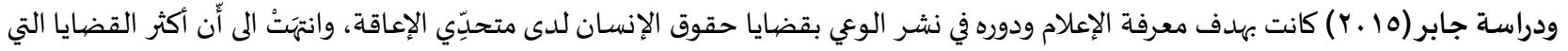

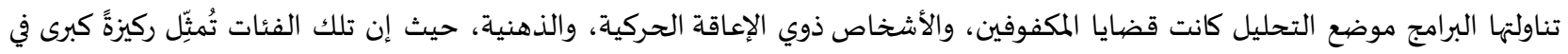

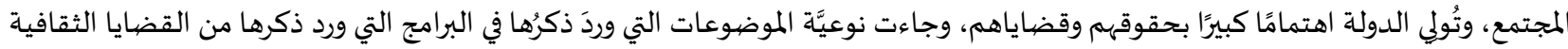

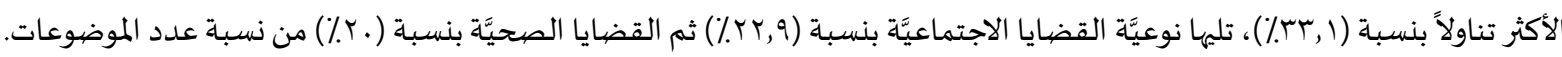

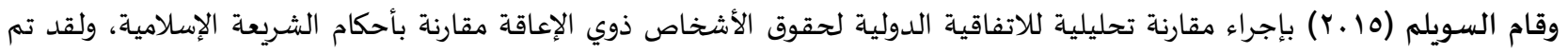
استخدام المنهج الاستقرائي التحليلي للنصوص الشرعية المتعلقة بالأشخاص ذوي الإعاقة، وكذلك بتحليل نص الاتفاقية الدولية لحقوق

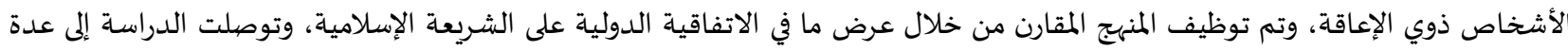

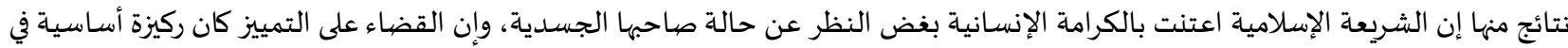
الدعوة إلى الدين الجديد وحضت على المساواة ولم تعرف نظام الفصل ولم تنظر إلى الإعاقة بوصفها خلل جسماني بمعزل عن العوائق المحيطة وعرفت التجهيزات المعقولة بأدق التفاصيل. 
• أما دراسة ابراهيم (10 • ب) والتي جاءت بهدف التعرف على مساهمة طريقة تنظيم المجتمع في تدعيم ثقافة حقوق الأطفال ذوي الاحتياجات الخاصة، وينبثق عن الهدف الرئيسي مجموعة من الأهداف الفرعية وهي: التعرف على المهارات والأدوات المهنية التي ينبني على المنظم الاجتماعي

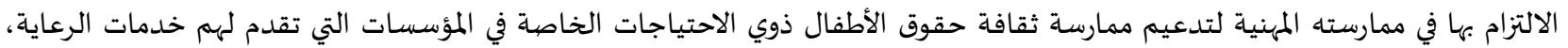

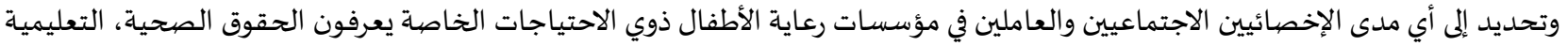

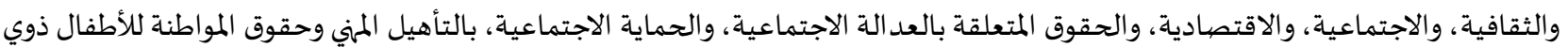
الاحتياجات الخاصة. وتوصلت الدراسة إلى أنّ أول المهارات المهنية التي ينبغي على المنظم الاجتماعي الالتزام بها هي (المهارة في تعليم الأطفال ذوي

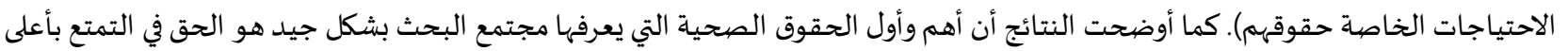
مستوى من الرعاية الصحية، وأن أهم وأول الحقوق التعليمية هو الحق في التعليم والتدريب، وأن أهم وأول الحقوق الاجتماعية هو الحق في

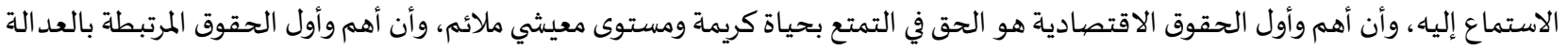

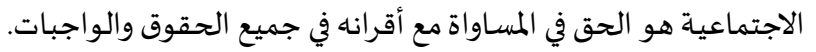

وقد أجرى شارما (Sharma,2015) دراسة لمعرفة تقييم مستويات الوعي بحقوق الأطفال المعاقين لدى الآباء والأمهات في مدينة بومباي بالهند وفي

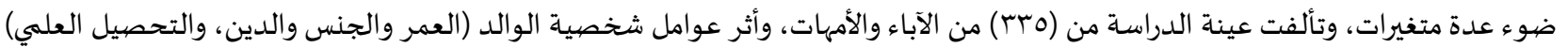

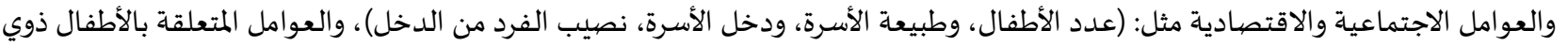

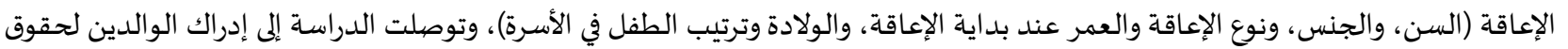

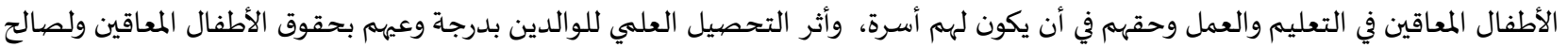

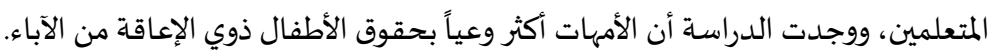
وقد أجرى ليونارد ولي (Lewnard\& Lee,2013) دراسة استهدفت الكشف عن معرفة المعلمين بحقوق الأطفال متعددي الإعاقة في الدمج بالمدارس العادية بولاية كاليفورنيا، وتألفت عينة الدراسة من (.بوج) معلم ومعلماة، وتوصلت الدراسة في نتائجها إلى أن درجة معرفة المعلمين

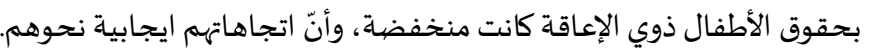
وجاءت دراسـة ضرار (ع ا ـ Y) للتعرف على مستوى معرفة مديري ومعلمي المدارس التي يتوفر فيها غرف المصادر في محافظة عمان ومحافظة مأدبا

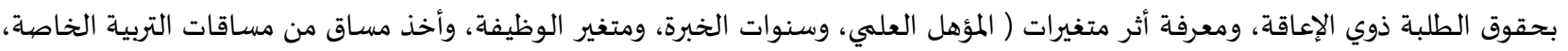

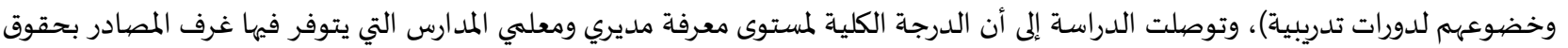
ذوي الإعاقة جاءت بدرجة متوسطة وتبين وجود فروق تبعًا لـ (المؤهل العلمي، وسنوات الخبرة وأحذ مساقات في التربية الخاصة وأخذ دورات

تدربيية).

أما دراسـة دويكات ومغربي (عا ـ ب) فقد هدفت إلى التعرف إلى مدى تضمين حقوق الأشخاص ذوي الإعاقة في المنهاج الفلسطيني، وتحديداً منهاج

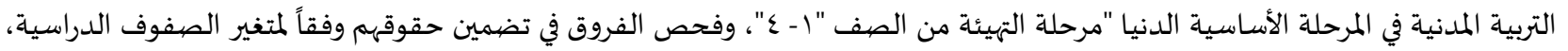

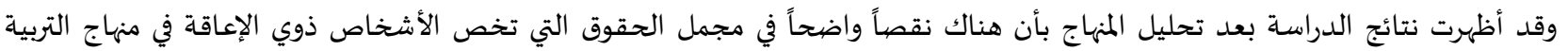
المدنية، وتكريس لصور نمطية محددة: (الإعاقة الحركية ،والإعاقة البصرية)، واختلاف في استخدام المصطلح في مباحث التربية المدنية كافة في

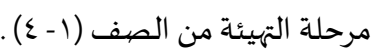

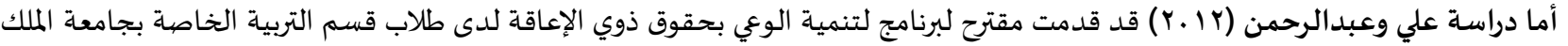
سعود بمدينة الرياض، وكشفت نتائج الدراسة عن فعالية البرنامج في تنمية الوعي بحقوق ذوي الإعاقة لدى طلاب قسم التربية الخاصية بجامعاة الملك سعود، وفي بقاء أثر التعلم. ولخص ماتشيدو (Matshedisho, 2007) وضع حقوق ذوي الإعاقة في التعليم العالي في الولايات المتحدة الأمريكية والمملكة المتحدة وجنوب

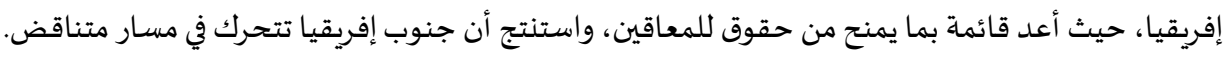
وعن حقوق ذوي الإعاقة في الفقه الاسلامي، جاءت دراسة الدهاشمة (11 ـ ب) لتبين حقوق ذوي الإعاقة الاجتماعية في الفقه الإسلامي والقانون

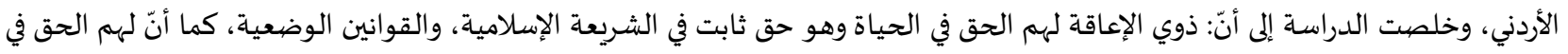

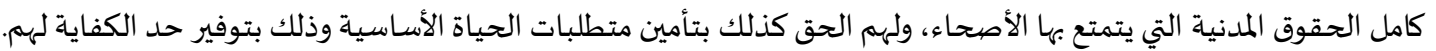


منهجية الدراسة واجراءاتها الميدانية:

منهجج الدراسـة: اتبعت الباحثتان في هذه الدراسة المنهج الوصفي التحليلي، وذلك لملائمته طبيعة متغيرات الدراسة واسئلة وأهد اف الدراسة.

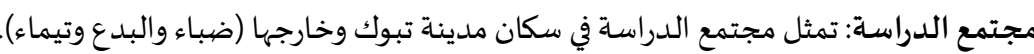

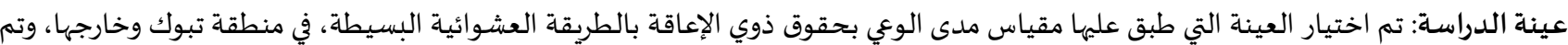

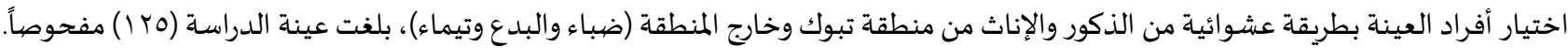
خصائص عينة الدراسةة: يمكن توضيح خصائص عينة الدراسة كما يلي: جدول (1) : توزيع أفراد عينة الدراسة وفقاً لمتغير المرحلة العمرية

\begin{tabular}{|c|c|c|}
\hline النسبة & العدد & المرحلة العمرية \\
\hline$\% r V, r$ & $r \varepsilon$ & من (.r- . .r) سنوات \\
\hline \% $\varepsilon r, \varepsilon$ & or & من (آ- . ع) سنوات \\
\hline$\%$ \% ,,$\varepsilon$ & r & من (اع- .0) سنوات \\
\hline$\% 0,7$ & $v$ & من (10 - .7) سنوات \\
\hline$\%, \varepsilon$ & $r$ & أكبر من • 7 سنة \\
\hline$\% 1$. & 1ro & المجموع \\
\hline
\end{tabular}

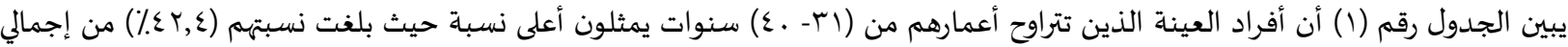

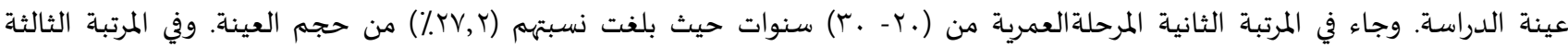

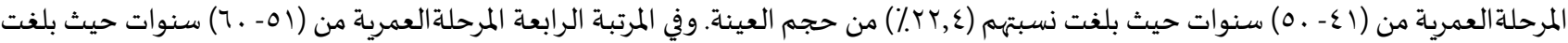

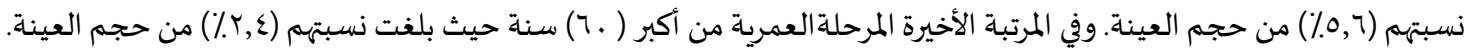

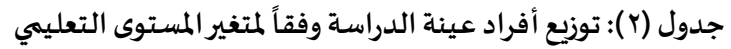

\begin{tabular}{|c|c|c|}
\hline النسبة & العدد & المستوى التعليهى \\
\hline$\% \varepsilon, \Lambda$ & 7 & أمي \\
\hline$\% 1, \varepsilon$ & ir & ابتدائي \\
\hline$\%(r, 1,7$ & TV & متوسط \\
\hline$\%$ & $v \varepsilon$ & جامعي \\
\hline$\% \varepsilon$ & 。 & فوق الجامعي \\
\hline$\% \ldots$ & 1 ro & المجموع \\
\hline
\end{tabular}

يبين الجدول رقم (ץ) أن المستوى التعليمي للحاصلين على مستوى ( جامعي) يمثلون أعلى نسبة حيث بلغت نسبتهم (r,09\%) من إجمالي عينة

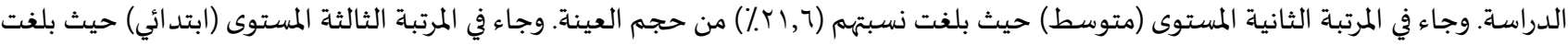

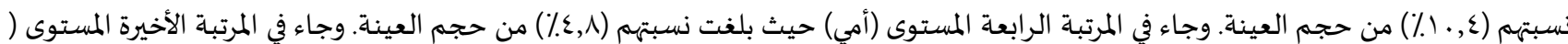
فوق الجامعي) حيث بلغت نسبتهم (ع.) من حجم العينة. ومن الملاحظات أنه لم يكن من أفراد عينة الدراسـة من يحمل المؤهل (ثانوي).

\begin{tabular}{|c|c|c|}
\hline النسبة & العدد & نوع العمل \\
\hline$\%, r \varepsilon, \Lambda$ & $r$ & معلم \\
\hline$\%$ \% r,A & $\varepsilon 1$ & موظف \\
\hline \% $\mid \varepsilon r, \varepsilon$ & or & لا يعمل \\
\hline$\%$ & ITo & المجموع \\
\hline
\end{tabular}

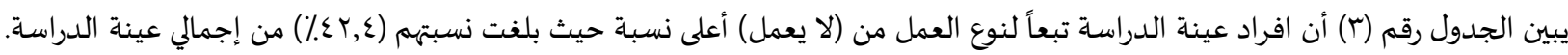

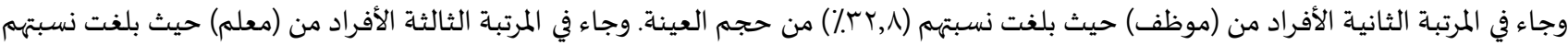

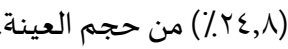


جدول (ع): توزيع أفراد عينة الدراسة وفقاً لمتغير المنطقة

\begin{tabular}{|c|c|c|}
\hline النسبة & العدد & المنطقة \\
\hline$\%$ ॠ , \& & 91 & تبوك \\
\hline$\%$ & $\wedge$ & البدع \\
\hline$\%$ & v & تيماء \\
\hline $1 ., 7$ & Ir & ضباء \\
\hline$\% \ldots$ & lro & المجمموع \\
\hline
\end{tabular}

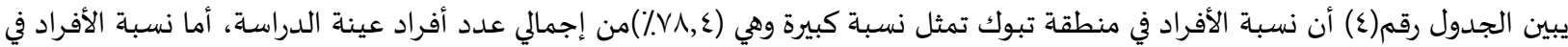

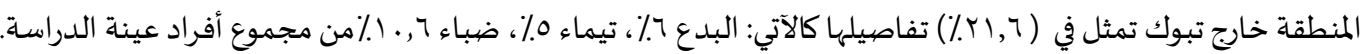
جدول (0): توزيع أفراد عينة الدراسة وفقاً لمتغير النوع

\begin{tabular}{|c|c|c|}
\hline النسبة & العدد & متغير الجنس \\
\hline$\% \varepsilon r, r$ & $0 \leqslant$ & ذكور \\
\hline$\% .07,1$ & vi & إناث \\
\hline$\% \ldots$ & iro & المجموع \\
\hline
\end{tabular}

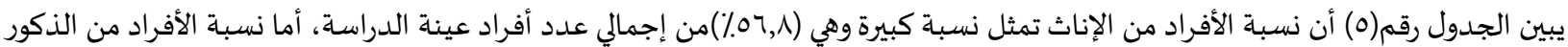

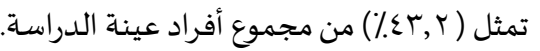

أداة الدراسـة:

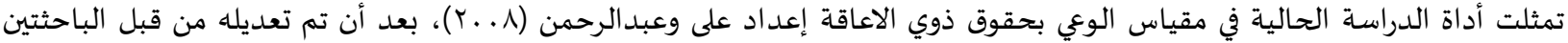

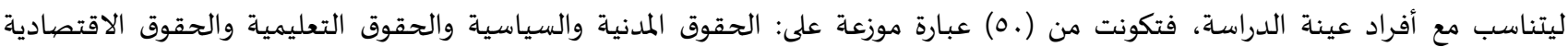
والاجتماعية والثقافية، تم توزيعاه على عدد من المحكمين من المتخصصين التربية الخاصية وعلم النفس التربوي والقياس والتقويم. تكون مقياس الوعي

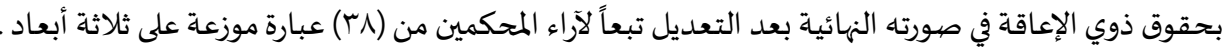
جدول (7): توزيع عبارات المقياس على الأبعاد

\begin{tabular}{|c|c|c|}
\hline أرقام العبارات & البعد & م \\
\hline ا إن إلى 10 & الحقوق المدنية والسياسية & 1 \\
\hline من 17 إلى To & الحقوق التعليمية & r \\
\hline من جr إلى Nبr & الحقوق الاقتصادية والاجتماعية والثقافية & $r$ \\
\hline
\end{tabular}

الخصيائص القياسية للمقياس:

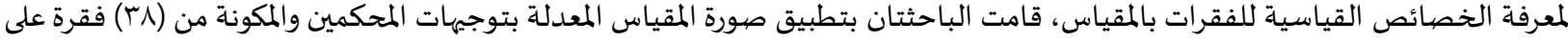
عينة أولية حجمها (·r) مفحوصًا تم اختيارهم بالطريقة العشوائية من مجتمع الدراسـة الحالية، وبعد تصحيح الاستجابات قامت الباحثتان برصديد الدرجات وإدخالها في الحاسب الآلي، ومن ثم تم إيجاد الآتي: صددق الاتساق الداخلي للفقرات: لمعرفة صداق اتساق الفقرات مع الدرجة الكلية بالمقياس بمجتمع الدراسة الحالية، تم حساب معامل ارتباط بيرسون بين درجات كل فقرة مع

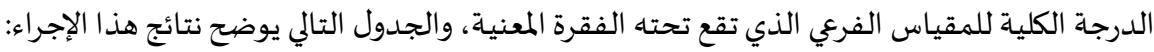
جدول(V): يوضح معاملات ارتباط الفقرات مع الدرجة الكلية بالمقياس بمجتمع الدراسة الحالية (ن =.بr)

\begin{tabular}{|c|c|c|c|c|c|c|c|}
\hline الارتباط & البند & الارتباط & البند & الارتباط & البند & الارتباط & البند \\
\hline$*, \ldots$ & $r$ & ., YYq & ri &., 0 , & 11 & $*_{.}, .199$ & 1 \\
\hline ., $\leqslant \vee$. & rr & $*_{., ., 9 .-}$ & rr & . TIY & Ir & ., rqY & $r$ \\
\hline$*_{., .}{ }^{*}$ & rr &.,$Y \varepsilon \wedge$ & 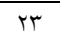 & $*_{., ., Y \Lambda}$ & $\pi$ & . & $r$ \\
\hline זrז, & $r \varepsilon$ & 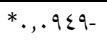 & $T \varepsilon$ & ${ }^{*}, ., 47$ & $1 \varepsilon$ & $*^{*}$, ,.人r & $\varepsilon$ \\
\hline ., \&०Y & ro & $* ., .1 \varepsilon$ & ro & $*_{., .}, 1$. & 10 & $*_{.}, .9$. & 0 \\
\hline מגו, & $r$ & . YTV & r &., $0 . £$ & 17 & . $T \leqslant Y$ & 7 \\
\hline., 19 & $r v$ & $*_{.}^{*}, .7$. & $T V$ & .,$\& 17$ & IV & ., & $v$ \\
\hline \multirow[t]{3}{*}{., हqभ } & $r_{\Lambda}$ & . $\{\varepsilon \wedge 0$ & rM & . & 11 &., 194 & $\Lambda$ \\
\hline & & .,707 & rq & $*_{.}^{*}, .7$. & 19 & . TEY & 9 \\
\hline & &., 0.1 & $r$. &., 111 & r. & *.,. Vo & 1. \\
\hline
\end{tabular}


يلاحظ من الجدول السـابق أن معاملات ارتباطات عدد من الفقرات دالة إحصائياً عند مستوى (0. . .) وأن هناك الفقرات تتمتع بصددق اتساق

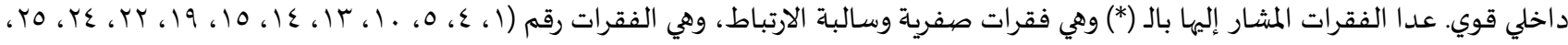

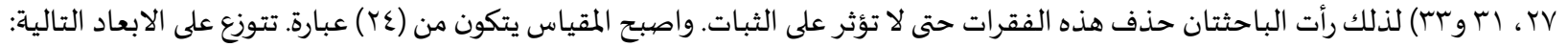
1. الحقوق المدنية والسياسية (1 )عبارات

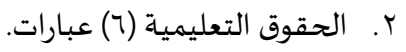

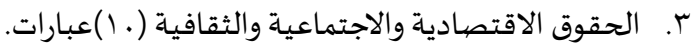

معاملات الثبات للمقياس:

لمعرفة الثبات للدرجة الكلية للمقياس في صورته الههائية المكونة من (عات آنقرة في مجتمع الدراسة الحالية، قامت الباحثتان بتطبيق معادلة الفا

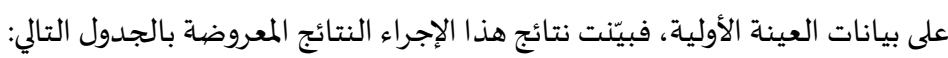

جدول (^): يوضيح نتائج معاملات الثبات للأبعاد الفرعية والدرجة الكلية بمقياس مجتمع الدراسة الحالية

\begin{tabular}{|c|c|c|c|}
\hline \multicolumn{2}{|c|}{ الخصائص القياسية } & \multirow[t]{2}{*}{ عدد الفقرات } & \multirow[t]{2}{*}{ المقاييس الفرعية } \\
\hline الصداق & الفا ل الفا & & \\
\hline., $91 \varepsilon$ & , ITV & $r \varepsilon$ & \\
\hline
\end{tabular}

نلاحظ من الجدول أعلاه تمتع اداة الدراسة بمعاملات صددق وثبات عالية.

أساليب المعالجة الإحصيائية:

استخدمت الباحثتان أساليب إحصائية متعددة لحساب نتائج الدراسة، وهي: المتوسطات والانحرافات المعيارية، واختبار "ت" لعينة واحدة واختبار "ت" لعينتين منفصلتين، وتحليل التباين الأحادي ( ANOVA).

\section{عرض نتائج الدراسة ومناقشتها:}

فيما يلي عرض وتحليل ومناقشـة النتائج التي توصلت إليها هذه الدراسة من إجابات أفراد العينة على عبارات المقياس، وقد تم عرض وتحليل كل سؤال من أسئلة الدراسة على حدة على النحو التحالي. السؤال الأول: ما مدى وعي سكان منطقة تبوك بحقوق الأشخاص ذوري الإعاقة؟

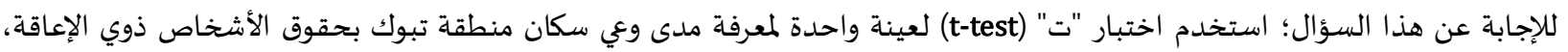

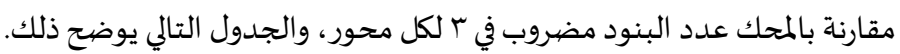
جدول (9): قيم "ت" لمستوى وعي سكان منطقة تبوك بحقوق الأشخاص ذوي الإعاقة

\begin{tabular}{|c|c|c|c|c|c|c|c|c|c|}
\hline الاستنتاج & الاحتمالية & الحربة & قيمة "ت" & المحك & $\begin{array}{c}ت \\
\text { الانحراف }\end{array}$ & المتوسط & 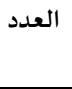 & محاور المقياس & م \\
\hline ارتفاع المستوى &.,$\ldots 1$ & IY & $r V, r$. & $r \varepsilon$ & $r, q 1$ & $r r, 0 \varepsilon$ & $1 r 0$ & الحقوق المدنية والسياسية. & 1 \\
\hline ارتفاع المستوى & $\ldots, \ldots 1$ & ITE & $r 0, V 7$ & 11 & $r, \ldots$ & $r \varepsilon, q 1$ & $1 Y 0$ & الحقوق التعليمية. & $r$ \\
\hline ارتفاع المستوى &.,$\ldots 1$ & ITE & Tr,o. & $r$ r. & $\varepsilon, q Y$ & $\varepsilon \varepsilon, V r$ & 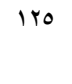 & والاجتماعية والثقافية. & $r$ \\
\hline ارتفاع المستوى &,$\ldots 1$ & IrE & rV,OY & Vr & $9, Y 9$ & $1 . r, 11$ & $1 Y 0$ & بحقى وعي سكان منطقة تبوك & $\varepsilon$ \\
\hline
\end{tabular}

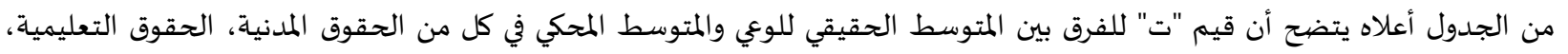

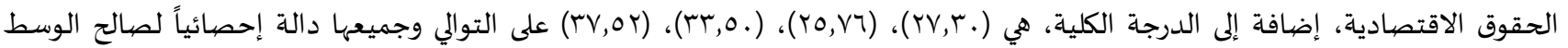
الحقيقي مما يشير إلى ارتفاع مستوى وعي سكان منطقة تبوك بحقوق الأشخاص ذوري الإعاقة.

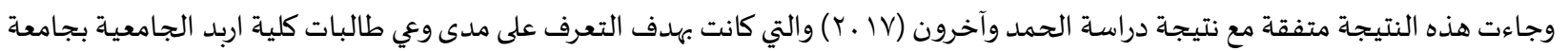
البلقاء بالأردن بحقوق ذوي الاعاقة، فأشارت نتائجها إلى أن درجة وعي الطالبات بحقوق الأشخاص ذوي الإعاقة (الشخصية والسياسية والاجتماعية

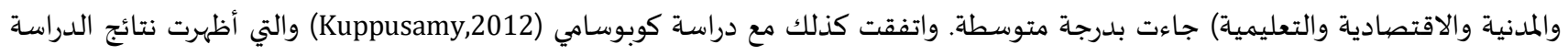

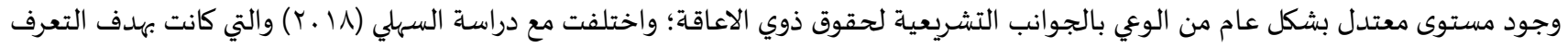

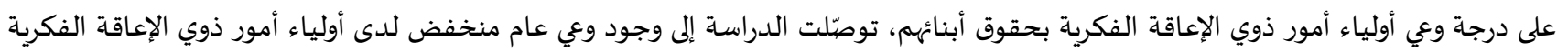


بحقوق أبنائهم، ماعدا الحقوق التعليمية كان الوعي فيها مرتفعاً. كما أظهرت الدراسة أن الحقوق التعليمية هي الأكثر وعياً لديهم، وتأتي بعدها الحقوق

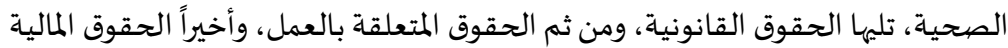
وتفسر الباحثتان ارتفاع الوعي بدرجة معقولة بحقوق ذوي الإعاقة بمنطقة تبوك، للبرامج التوعوية والتثقيفية التي نظمتها تنظيمات وتكوينات مجتمع منطقة تبوك في مجال رفع الوعي بحقوق ذوي الاعاقة ممثل في كلية تنمية المجتمع بجامعة تبوك، وجمعيات ذوي الإعاقة بالمنطقة، إضافة إلى

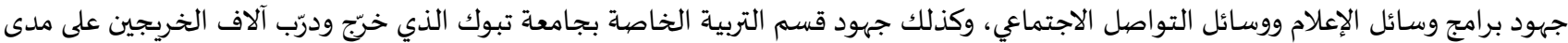
عشر سنوات ماضية، ولعلهم مثلوا أداة للوعي ونشر ثقافة احترام وجود حقوق ذوي الإعاقة.

ثانياً: للإجابة عن السؤال الثاني : هل توجد فروق في مدى الوعي بحقوق ذوي الإعاقة تعزى للمنطقة (تبوك- خارج تبوك)؟ لإجابة عن السؤال الثاني تم التحقق من إجابة السؤال الثاني باستخدام اختبار "ت" (t-test) لعينتين منفصلتين (تبوك - خارج تبوك) ويوضح

الجدول ( • (1) النتيـجة.

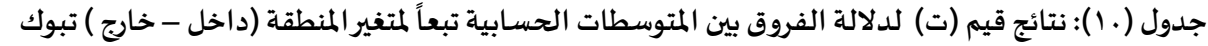

\begin{tabular}{|c|c|c|c|c|c|c|c|c|c|}
\hline الاستنتاج & الاحتمالية & الحربة & "قيمة & المعياري & المتوسط المسابي & العدد & السكن & الوعي بالحقوق & رقم \\
\hline \multirow{2}{*}{ توجد فروق لصبالح خارج } & \multirow[t]{2}{*}{$\ldots 1$} & \multirow[t]{2}{*}{ ITr } & \multirow[t]{2}{*}{$\varepsilon, \pi$} & $r, 19$ & Tr,Ar & 91 & داخل & \multirow[t]{2}{*}{ المدنية والسياسية } & 1 \\
\hline & & & & $r, 77$ & $r 7,19$ & TV & خارج & & \\
\hline \multirow{2}{*}{ توجد فروق لصالح خارج } & \multirow{2}{*}{$\ldots, \ldots 1$} & \multirow[t]{2}{*}{ Ir } & \multirow[t]{2}{*}{$r, 10$} & $T, V \varepsilon$ & $r \varepsilon, \varepsilon$. & 91 & داخل & \multirow[t]{2}{*}{ التعليمية } & $r$ \\
\hline & & & & $r, r)$ & $\mathrm{rT,V \Lambda}$ & TV & خارج & & \\
\hline \multirow{2}{*}{ توجد فروق لصبالح خارج } & \multirow[t]{2}{*}{., } & \multirow[t]{2}{*}{ ITr } & \multirow[t]{2}{*}{$r, r)$} & $0, \cdot r$ & $\varepsilon \varepsilon, Y$. & 91 & داخل & \multirow{2}{*}{ الاقتصادية الاجتماعية } & $r$ \\
\hline & & & & $r, 99$ & $\varepsilon 7,7 T$ & rV & خارج & & \\
\hline \multirow{2}{*}{ توجد فروق لصالح خارج } & \multirow[t]{2}{*}{$\ldots 1$} & \multirow[t]{2}{*}{ IrT } & \multirow[t]{2}{*}{$\varepsilon, \pi r$} & $\lambda, V \varepsilon$ & $1.1, \varepsilon r$ & 91 & داخل & \multirow[t]{2}{*}{ المقياس ككل } & $\varepsilon$ \\
\hline & & & & 1,01 & $1.9,09$ & $r V$ & خارج & & \\
\hline
\end{tabular}

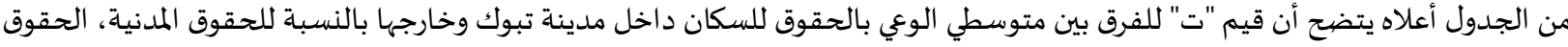

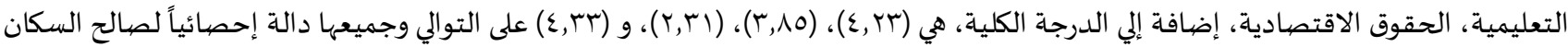
خارج تبوك، مما يشير إلى ارتفاع مستوى وعي السكان خارج منطقة تبوك بحقوق الأشخاص ذوي الإعاقة. أكثر من سكان تبوك. ترى الباحثتان أنّ

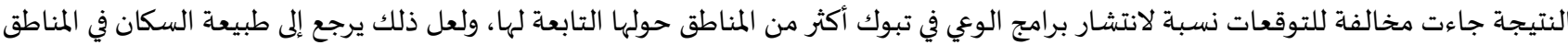

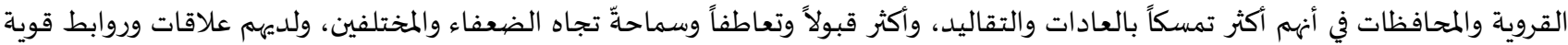
أدت إلى التماسك والترابط والتعاون والتعاضد بينهم، بغض النظر عن درجة اختلافهم، أكثر من سكان المدن الذين طغت عليهم حياة المدنية والحياة

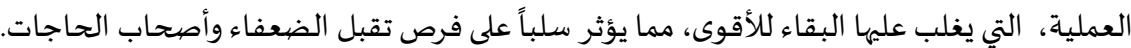

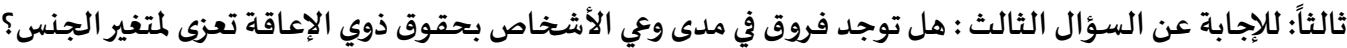

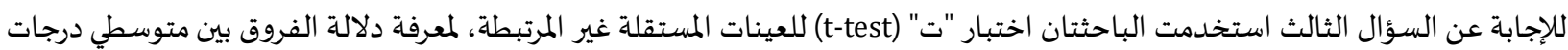
الأشخاص تبعاً لمتغير الجنس، يوضح الجدول (1 الن النتيجة.

جدول (11): نتائج قيم (ت) لدلالة الفروق بين المتوسطات الحسابية تبعاً لمتغير الجنس المس المبل

\begin{tabular}{|c|c|c|c|c|c|c|c|c|c|}
\hline الاستنتاج & الاحتمالية & الحربة & "تيمة & الانحراف & المستوسط المسي & العدد & الجنس & الوعي بالحقوق & رقم \\
\hline \multirow{2}{*}{ توجد فروق لصالح } & \multirow[t]{2}{*}{.,.$\leqslant r$} & \multirow[t]{2}{*}{ Irr } & \multirow[t]{2}{*}{$r, . \varepsilon$} & $r, 97$ & $r \varepsilon, r_{0}$ & of & ذكور & \multirow[t]{2}{*}{ المدنية والسياسية. } & 1 \\
\hline & & & & r, YA & $r T, q T$ & ni & إناث & & \\
\hline \multirow{2}{*}{ لا توجد فروق } & \multirow[t]{2}{*}{., 911} & \multirow[t]{2}{*}{ IrT } & \multirow[t]{2}{*}{.,.$r$} & $r, \leq \varepsilon$ & $T \varepsilon, q 1$ & o\& & ذكور & \multirow[t]{2}{*}{ التعليمية. } & $r$ \\
\hline & & & & $r, 7 \varepsilon$ & $T \varepsilon, q Y$ & n & إناث & & \\
\hline \multirow[t]{2}{*}{ لا توجد فروق } & \multirow[t]{2}{*}{.,$V Y \varepsilon$} & \multirow[t]{2}{*}{ ITr } & \multirow[t]{2}{*}{ ד } & $0, V \varepsilon$ & $\{\varepsilon, 91$ & o\& & ذكور & \multirow{2}{*}{ الاقتصادية الاجتماعية } & $r$ \\
\hline & & & & $\varepsilon, Y Y$ & $\{\varepsilon, 09$ & n & إناث & & \\
\hline \multirow[t]{2}{*}{ لا توجد فروق } & \multirow[t]{2}{*}{.,$r \cdot \varepsilon$} & \multirow[t]{2}{*}{ ITr } & \multirow[t]{2}{*}{$1, . r$} & $1 ., 9$ & $1 . \varepsilon, 1 V$ & os & ذكور & \multirow[t]{2}{*}{ المقياس ككل } & $\varepsilon$ \\
\hline & & & & $v \cdot, \lambda 7$ & 1. $\mathrm{r}, \varepsilon \varepsilon$ & n & إناث & & \\
\hline
\end{tabular}

من الجدول أعلاه يتضيح أن قيم "ت" للفرق بين متوسطي الوعي بالحقوق للسكان بين الذكور والإناث في مدينة تبوك وخارج مدينة توك بالنسبة

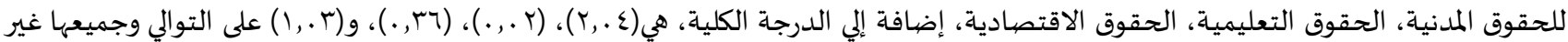
دالة إحصائياً إلا في محور الوعي بالحقوق المدنية والسياسية لصالح الذكور، ما يشير إلى ارتفاع مستوى وعي الذكور بالحقوق المدنية والسياسية، أكثر

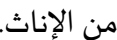


رابعاً: للإجابة عن السؤال الر ابع: هل توجد فروق في مدى وعي الأشخاص بحقوق ذوي الإعاقة تعزى لمتغير المرحلة العمرية؟ للإجابة عن السؤال الرابع استخدمت الباحثتان اسلوب تحليل التباين من الدرجة الأولى كروسكال - واليز لمعرفة دلالة الفروق بين متوسطي

درجات الأشخاص في مقياس الوعي بحقوق ذوي الإعاقة تعزى لمتغير المرحلة العمرية، ويوضح الجدول (r ا ) النتيجة.

جدول (r ا ): نتائج تحليل التباين من الدرجة الأولى لكروسكال - واليزلمعرفة دلالة الفروق حسب الفئة العمرية

\begin{tabular}{|c|c|c|c|c|c|c|c|}
\hline التفسير & الاحتمالية & درجات الحرية & SL & متوسط الرتب & العدد (ن) & الفئة العمرية & البعد \\
\hline \multirow{5}{*}{ لا لورجد } & \multirow[t]{5}{*}{., 101} & \multirow[t]{5}{*}{$\varepsilon$} & \multirow[t]{5}{*}{1, rod } & $7 r, 0$. & $r \varepsilon$ & $r .-r$. & \multirow{5}{*}{ السياسية } \\
\hline & & & & $7 r, \varepsilon$. & or & $\varepsilon .-r)$ & \\
\hline & & & & 70,19 & ru & $0 .-\varepsilon 1$ & \\
\hline & & & & $\varepsilon \wedge, 7 \varepsilon$ & 7 & $7 .-01$ & \\
\hline & & & & $71,1 \mathrm{~V}$ & $r$ & . 7 من أكبر. & \\
\hline \multirow{5}{*}{ لا لا فرجد } & \multirow[t]{5}{*}{. } & \multirow[t]{5}{*}{$\varepsilon$} & \multirow[t]{5}{*}{$r, 7.0$} & $71, \lambda \mathrm{V}$ & $r \varepsilon$ & r.-r. & \multirow{5}{*}{ التعليمية } \\
\hline & & & & $7 r, \mathrm{Vr}$ & or & $\varepsilon .-r)$ & \\
\hline & & & & 71,71 & ru & $0 .-\varepsilon 1$ & \\
\hline & & & & $O r, \Lambda T$ & 7 & $7 .-01$ & \\
\hline & & & & $9 \Lambda, \lambda r$ & $r$ & . 7 من أكبر. & \\
\hline \multirow{5}{*}{ لا فروقد } & \multirow[t]{5}{*}{., \&०r } & \multirow[t]{5}{*}{$\varepsilon$} & \multirow[t]{5}{*}{$r, 779$} & $71, . r$ & $r \varepsilon$ & r.-r. & \multirow{5}{*}{ والاقتصـادية } \\
\hline & & & & $7 T, \varepsilon \varepsilon$ & or & $\varepsilon .-r)$ & \\
\hline & & & & $07,0 \varepsilon$ & ru & $0 .-\varepsilon 1$ & \\
\hline & & & & $07, \varepsilon r$ & v & $7 .-01$ & \\
\hline & & & & $91,0$. & $r$ & . 7 من أكبر. & \\
\hline \multirow{5}{*}{ لا لاتوجد } & \multirow[t]{5}{*}{.,017 } & \multirow[t]{5}{*}{$\varepsilon$} & \multirow[t]{5}{*}{$r, 1 r}$. & $7 \varepsilon, 7 \uparrow$ & $r \varepsilon$ & $r .-r$. & \multirow[t]{5}{*}{ الحقوق الكلية } \\
\hline & & & & $T r, Y \varepsilon$ & or & $\varepsilon .-r \mid$ & \\
\hline & & & & $71, \mathrm{~V}$. & ru & $0 .-\varepsilon 1$ & \\
\hline & & & & $\{7, \wedge\rceil$ & v & $7 .-01$ & \\
\hline & & & & $19,7 \mathrm{~V}$ & $r$ & . 7 من أكبر & \\
\hline
\end{tabular}

من الجدول أعلاه يتضح أن قيم "كاب" للفرق بين متوسطات الفئات العمرية في الوعي بالحقوق للسكان في مدينة تبوك وخارج مدينة تبوك

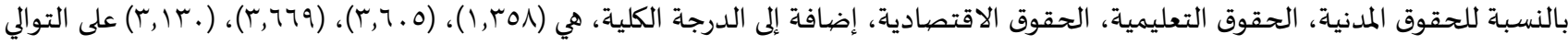

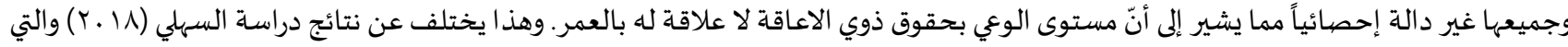

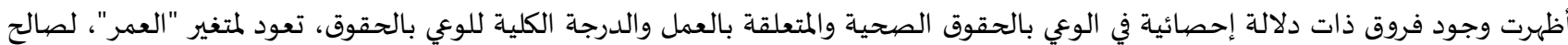

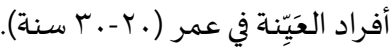

خامساً: للإجابة عن السؤال الخامس: هل توجد إند فروق في مدى وعي الأشخاص بحقوق ذوي الإعاقة تعزى لمتغير المستوى التعليمي؟ لإجابة عن السؤال الخامس استخدمت الباحثتان أسلوب تحليل التباين من الدرجة الأولى كروسكال - واليز لمعرفة دلالة الفروق بين متوسطي درجات الأشخاص في مقياس الوعي بحقوق ذوي الإعاقة تعزى لمتغير المستوى التعليمي، ويوضح الجدول (rاس ال النتيجة.

جدول (r ا ): نتائج تحليل التباين من الدرجة الأولى لكروسكال - واليزلمعرفة دلالة الفروق حسب المستوى التعليمي

\begin{tabular}{|c|c|c|c|c|c|c|c|}
\hline التفسير & الاحتمالية & درجات الحرية & Sו & متوسط الرتب & العدد (ن) & المستوى التعليمي & البعد البعد \\
\hline \multirow{5}{*}{ لا توجد } & \multirow[t]{5}{*}{. , rol } & \multirow[t]{5}{*}{$\varepsilon$} & \multirow[t]{5}{*}{$\varepsilon, \varepsilon Y V$} & $\varepsilon V, 7 \vee$ & 7 & أمي & \multirow{5}{*}{ الحقوق السياسية } \\
\hline & & & & 01,19 & $1 \pi$ & ابتدائي & \\
\hline & & & & $\Delta ৭, \wedge r$ & TV & متوسط & \\
\hline & & & & $77, r 1$ & $V \varepsilon$ & جامعي & \\
\hline & & & & A., r. & 0 & فوق الجامعي & \\
\hline \multirow{5}{*}{ لا توجد } & \multirow[t]{5}{*}{$\cdot, 7 \leqslant 7$} & \multirow[t]{5}{*}{$\varepsilon$} & \multirow[t]{5}{*}{$r, \sum 90$} & $07, \varepsilon r$ & 7 & أمي & \multirow[t]{5}{*}{ الحقوق التعليمية } \\
\hline & & & & Or,Tr & 14 & ابتدائي & \\
\hline & & & & $7 \varepsilon, .9$ & TV & متوسط & \\
\hline & & & & $\pi, \mathrm{VA}$ & $V \varepsilon$ & جامعي & \\
\hline & & & & $\Lambda \cdot, \varepsilon$. & 0 & فوق الجامعي & \\
\hline \multirow{2}{*}{ لا توجد } & \multirow[t]{2}{*}{., $90_{0}$} & \multirow[t]{2}{*}{$\varepsilon$} & \multirow[t]{2}{*}{. 1997} & $V Y, \Sigma T$ & 7 & أمي & \multirow{2}{*}{ والاجتماعية والثقافية الاقتصادية } \\
\hline & & & & $07,0$. & $1 \pi$ & ابتدائي & \\
\hline
\end{tabular}




\begin{tabular}{|c|c|c|c|c|c|c|c|}
\hline & & & & $7 \varepsilon, 79$ & TV & متوسط & \\
\hline & & & & $7 r, \Lambda T$ & $V \varepsilon$ & جامعي & \\
\hline & & & & 71,7 . & 0 & فوق الجامعي & \\
\hline \multirow{5}{*}{ لا فروقد } & \multirow[t]{5}{*}{., 01.} & \multirow[t]{5}{*}{$\varepsilon$} & \multirow[t]{5}{*}{$r, A V$. } & or,o. & 7 & أمي & \multirow[t]{5}{*}{ الحقوق الكلية } \\
\hline & & & & $0 ., \pi T$ & 15 & ابتدائي & \\
\hline & & & & $7 r, \Lambda 1$ & TV & متوسط & \\
\hline & & & & 70,11 & $V \varepsilon$ & جامعي & \\
\hline & & & & $V_{7}, \varepsilon$. & 0 & فوق الجامعي & \\
\hline
\end{tabular}

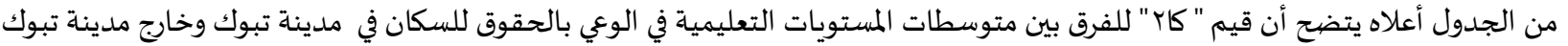

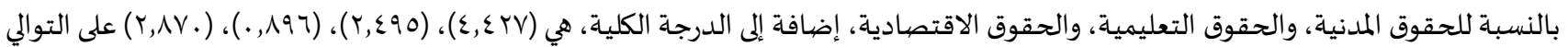

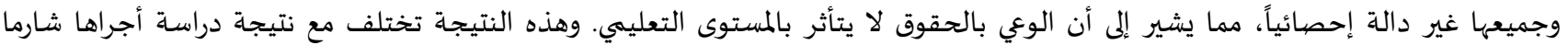
(Sharma,2015)

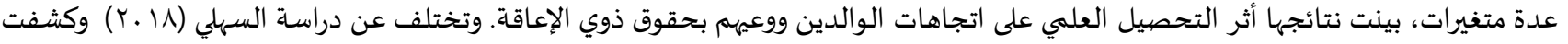

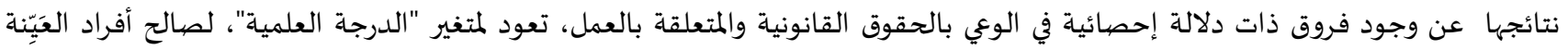

$$
\text { الحاصلين على (ابتدائي). }
$$

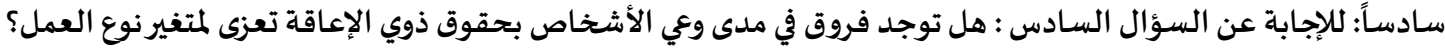

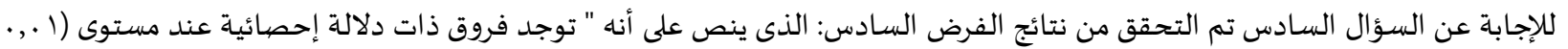

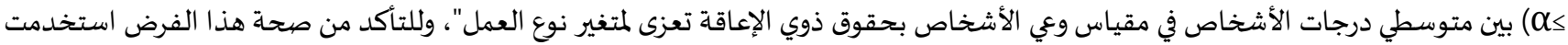

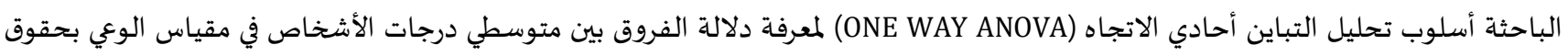
ذوي الإعاقة تعزى لمتغير نوع العمل (معلم، موظف، لا يعمل)،ويوضح الجدول ( ع () نتائج هذا الفرض. لإنان.

جدول (ع ): نتائج تحليل التباين الأحادي (ANOVA) لدلالة الفروق بين المتوسطات الحسابية في مقياس الوعي بحقوق ذوي الإعاقة تبعاً لمتغيرنوع العمل

\begin{tabular}{|c|c|c|c|c|c|c|c|c|}
\hline الاستنتاج & مستوى & ف & الحربة & متوسط المربعات & مجموع المربعات & التباين & الوعي بالحقوق & رقم \\
\hline \multirow[t]{3}{*}{ لا توجد فروق } & \multirow[t]{3}{*}{., 101} & \multirow[t]{3}{*}{$1, \lambda V$} & $r \wedge, 191$ & r & 07, rNr & بيني & \multirow{3}{*}{ والسياسية. } & \multirow[t]{3}{*}{1} \\
\hline & & & $10, \cdot v 1$ & IKT & INKA,7YO & داخل & & \\
\hline & & & & ITE & $11990, \ldots 1$ & الكلي & & \\
\hline \multirow[t]{3}{*}{ لا توجد فروق } & \multirow[t]{3}{*}{.,var } & \multirow[t]{2}{*}{. IT } & $r, 119$ & $r$ & $\varepsilon, r T V$ & بيني & \multirow[t]{3}{*}{ التعليمية. } & \multirow[t]{3}{*}{2} \\
\hline & & & 9,114 & ITr & 1111,190 & داخل & & \\
\hline & & & & $1 T \varepsilon$ & $1117, . \mathrm{rr}$ & الكلي & & \\
\hline \multirow[t]{3}{*}{ لا توجد فروق } & \multirow[t]{2}{*}{., ror } & \multirow[t]{2}{*}{$1, .0$} & ro, rMM & $r$ & $0 ., V V 7$ & بيني & \multirow{3}{*}{ الالاقتصاعية } & \multirow[t]{3}{*}{3} \\
\hline & & & $r \varepsilon, 1 \leqslant V$ & ITr & $r 9 \leqslant 0,9 \vee 0$ & داخل & & \\
\hline & & & & ITE & r997, VOr & الكلي & & \\
\hline \multirow[t]{3}{*}{ لا توجد فروق } & \multirow[t]{2}{*}{$\cdot, \wedge \cdot \varepsilon$} & \multirow[t]{2}{*}{., Tr } & 19,101 & $r$ & $r \Lambda, r 17$ & بيني & \multirow[t]{3}{*}{ المقياس ككل } & \multirow[t]{3}{*}{4} \\
\hline & & & $\Lambda V, \varepsilon \leq 7$ & IrT & $1.771, \varepsilon 0 \mathrm{r}$ & داخل & & \\
\hline & & & & $1 T \varepsilon$ & $1 \cdot v \cdot 7, v 71$ & الكلي & & \\
\hline
\end{tabular}

من الجدول أعلاه يتضح أن قيم "ف" للفرق بين متوسطات نوع العمل في الوعي بالحقوق للسكان في مدينة تبوك وخارج مدينة تبوك بالنسبة

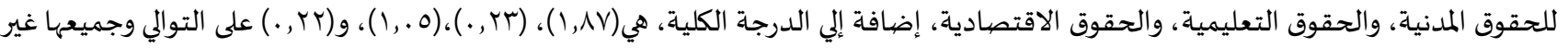

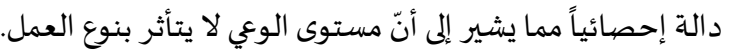
وتختلف هذه النتيجة مع نتيجة دراسة ليونارد ولي (Lewnard\& Lee,2013) والتي استهدفت الكشف عن معرفة المعلمين بحقوق الأطفال

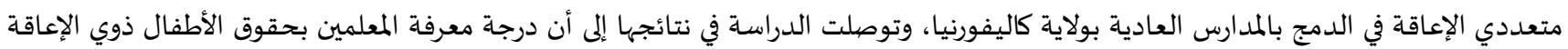
كانت منخفضة، إلا أنّ هناك اتجاهات إيجابية نحوهم.

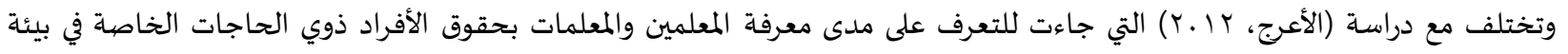
الممدرسة في مدينة بغداد، وتوصلت النتائج إلى أن معرفة المعلمين بحقوق الأفراد ذوي الحاجات المعات الخاصة كانت متدنية. 
ا. ارتفاع مستوى وعي سكان منطقة تبوك بحقوق الأشخاص ذوي الإعاقة.

r. توجد فروق في مدى الوعي بحقوق ذوي الاعاقة تعزى للمنطقة (تبوك- خارج تبوك) لصالح خارج تبوك.

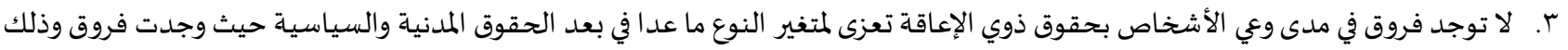
لصالح الاناث. ع. لا توجد فروق في مدى وعي الأشخاص بحقوق ذوي الإعاقة تعزى لمتغير المرحلة العمرية وذلك لصالح المرحلة العمرية.

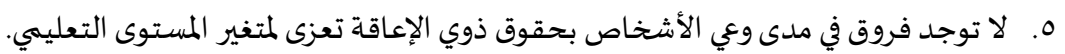
7. لا توجد فروق في مدى وعي الأشخاص بحقوق ذوي الإعاقة تعزى لمتغير نوع العمل.

التوصيات: 1. العمل على نشر حقوق الأشخاص ذوي الإعاقة على كافة مستويات المجتمع. r. تنظيم برامج التوعية بحقوق الأشخاص ذوي الإعاقة بكافة المستويات التعليمية من رياض الأطفال إلى المرحلة الجامعية. r. إدخال برامج ومساقات علمية على مستوى المدارس الثانوية والجامعات للتعريف بحقوق ذوي الإعاقة في التشريعات المحلية والدولية. ع. تشجيع برامج ذوي الإعاقة مع العاديين لتعزيز تقبلهم ومساهمتهم مع العاديين في حركة الحياة بالمجتمع. 0. ترسيخ مبدأ المشاركة المجتمعية لذوي الإعاقة في كل أنشطة المجتمع. 7 7. توفير عدد من الأنشطة الرياضية والترفيهية لذوي الإعاقة . V. تنظيم منافسات ومسابقات قومية تستوعب كافة فئات ذوي الإعاقة، لإبراز مواهبهم وإبداعاتهم، أسوة بأقرانهم العاديين.

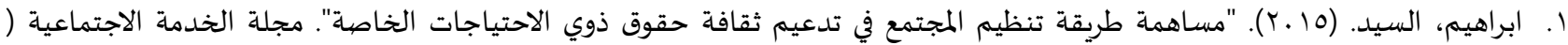

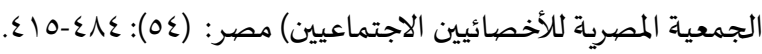

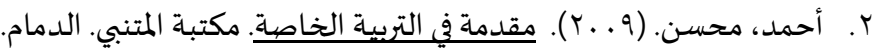

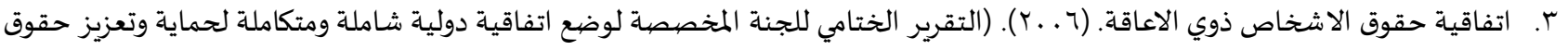
الأشخاص ذوي الإعاقة وكرامتهم).

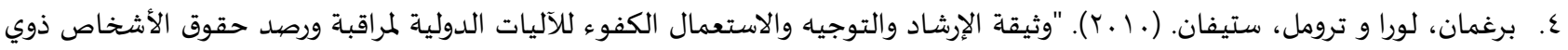

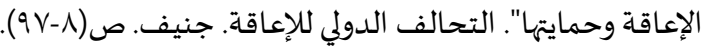

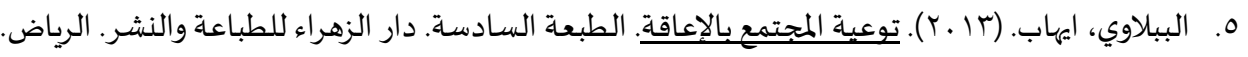

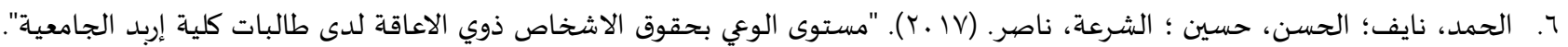

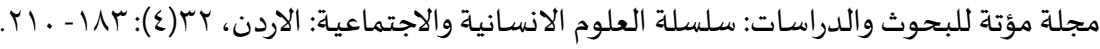

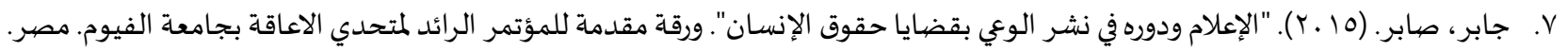
(alukah.net/social/0/105518//)

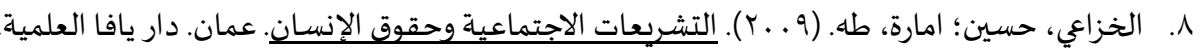
9.

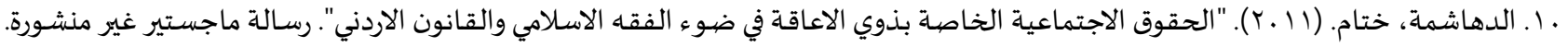

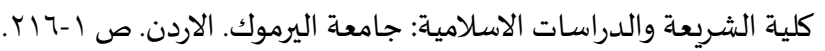
ا ا. دوبكات، فخري؛ مغربي، عبدالرحمن. (عا.ب). "مدى تضمين حقوق الاشخاص ذوي الاعاقة في منهاج التربية المدنية الفلسطيني في المرحلة

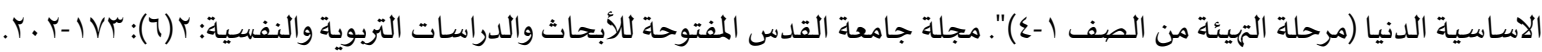

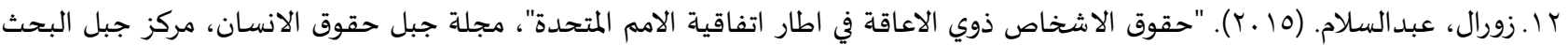

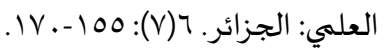
rا السهلي، سلمى. (1) . إ). "وعي أولياء أمور ذوي الإعاقة الفكرية في معاهد وبرامج التربية الفكرية بحقوق أبنائهم". رسالة ماجستير غير منشورة.

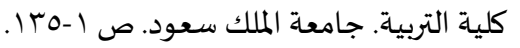


ع ا. السويلم، الشرفات. (10 ـ r). "دراسة تحليلية للاتفاقية الدولية لحقوق الاشخاص ذوي الاعاقة مقارنة بأحكام الشريعة الاسلامية". الاكاديمية

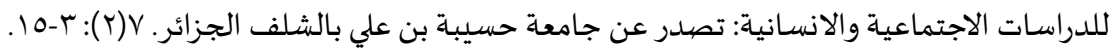

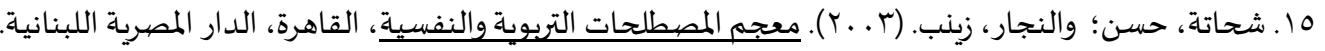

7 ا. شطوري، صلاح. (r ا ـr). "رعاية وتأهيل ذوي الإعاقة في ظل التشريعات والقوانين المصرية". موقع أطفال الخليج ذوي الاحتياجات الخاصة. http://www.gulfkids.com/vb/showthread.php?t=2525)

V ا ضرار، منياء. (ع ا . Y). "مستوى معرفة مديري ومعلمي المدارس التي يتوفر فهيا غرف المصادر بحقوق الطلبة ذوي الاعاقة". رسالة ماجستير غير

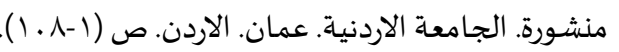

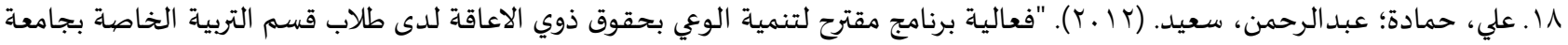

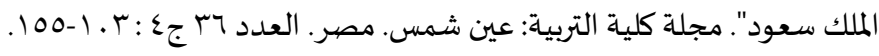

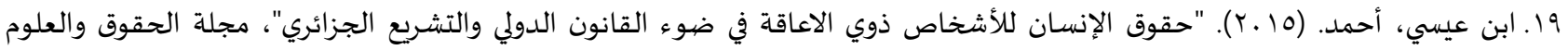

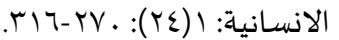

. . أبو غريب، عايده. (9 . . Y). "ورقة عمل بعنوان :حقوق الأشخاص ذوي الإعاقة على المستوى الدولي والعربي". المؤتمر العلمي الثاني للجمعية

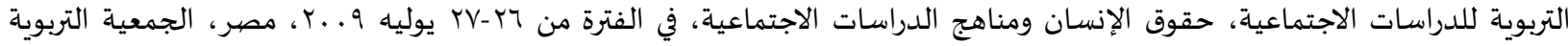

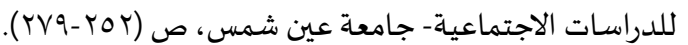

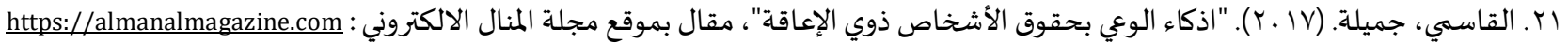

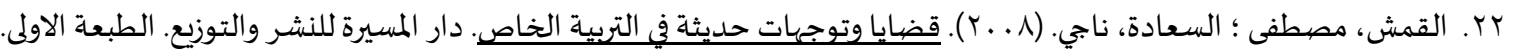

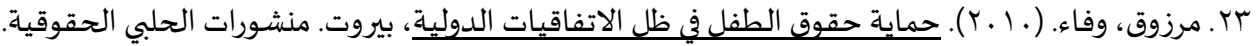

ثانياً: المراجع الأجنبية:

[1] Kuppusamy, B., Narayan, J., \& Nair, D. (2012). "Awareness among family members having children with mental retardation on relevant legislations in India". Educational Research and Reviews, 7(14): 326-331.

[2] Lewnard. S \& Lee. A. (2013). "The Teachers' knowledge of children's rights in the multi-disability the merger on the normal mandate of the California schools". Journal Disability Studies Quarterly, 31(2).

[3] Matshedisho, K. R (2007). "Access to Higher Education for Disabled Students in South Africa: A Contradictory Conjuncture of Benevolence. Rights and the Social Model of Disability". Disability\&Society, 22 (7): 685-699. https://doi.org/10.1080/09687590701659535.

[4] Rosli, HazlinFalina \& others (2017). "The Role of Media in Community Awareness Tow Ards The Right of Persons with Disablities (PWD)", Journal of Education and Social Sciences, 7(1): 67-73.

[5] Sharma. P. (2015). "Assessment of Awareness Levels of Parents - A Multivariate Approach". Sociology and Anthropology, 3(1): 58 - 72. https://doi.org/10.13189/sa.2015.030108.

[6] World Health Organization (2017). World report on disability, 2011. (https://ar.wikipedia.org/wikiA5).

[7] https//.www.un.org.

[8] http://boes.org/multiniguall 


$$
\text { المجلة الدولية للدراسـات التربوية والنفسية }
$$

International Journal of Educational \& Psychological Studies (EPS)

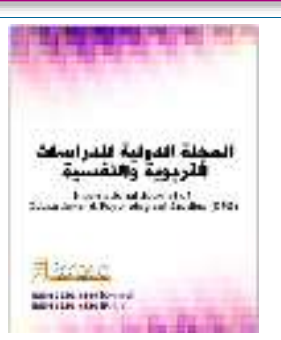

\title{
Tabuk residents' awareness of rights of people with disabilities
}

\author{
Huda Fadlallah Ali Mohammed
}

Assistant Professor of Special Education, Faculty of Education, University of Khartoum, Sudan Ahuda735@yahoo.com

\section{Najwa Sulaiman Muslim Almsoudi}

Special education teacher in Tabuk, KSA

\author{
Received : 22/4/2020 Revised : 5/5/2020 Accepted : 16/5/2020 DOI : https://doi.org/10.31559/EPS2021.9.1.15
}

Abstract: This study aimed at investigating the extent of Tabuk region citizen's awareness of rights of people with disabilities. The sample of the study was comprised of (125) subjects from Tabuk region residents who were of different ages and social, economic and professional levels, and who were simple randomly selected. The data collection tool was Awareness Abdalrahman (2008) and modified by the two researchers. The two researchers used several statistical methods to calculate the study findings These were: average, standard deviation, (T. test) for one sample, T.test for two independent samples, and Analysis of variance (ANOVA). and analysis of variance the first-class Kruskal-Wallis Test.

The study findings came to: there is High awareness of Tabuk citizens of people with disabilities' rights. There are differences in the extent of awareness of people with disabilities' rights attributed to the region (from / out of Tabuk) favoring out of Tabuk. There are no differences in the extent of awareness of Tabuk region as for people with disabilities' rights with regard to gender, except for some civilian and political rights where some differences were found in favor of females. And there are no differences in the extent of Tabuk citizens' awareness of people with disabilities' rights regarding age, education level, and work variables. In the light of these findings the study presented a number of recommendations.

Keywords: people with disabilities; awareness of people with disabilities' right; the rights of people with disabilities agreement.

\section{References:}

[1] 'ly, Hmadh: 'bdalrhmn, S'eyd. (2012). "F'alyt Brnamj Mqtrh Ltnmyh Alw'y Bhqwq Dwy Ala'aqh Lda Tlab Qsm Altrbyh Alkhash Bjam't Almlk S'ewd". Mjlt Klyt Altrbyh: 'yn Shms. Msr. Al'dd 36 J4 : 103-155.

[2] Abn 'ysy, Ahmd. (2015). "Hqwq Alensan Llashkhas Dwy Ala'eaqh Fy Dw' Alqanwn Aldwly Waltshry' Aljza'ry", Mjlt Alhqwq Wal'lwm Alansanyh: 1(24): 270-316.

[3] Abrahym, Alsyd. (2015). "Msahmt Tryqt Tnzym Almjtm' Fy Td'ym Thqafh Hqwq Dwy Alahtyajat Alkhash". Mjlt Alkhdmh Alajtma'eyh ( Aljm'yh Almsryh Llakhsa'yyn Alajtma'yyn) Msr: (54): 484-415.

[4] Ahmd, Mhsn. (2009). Mqdmh Fy Altrbyh Alkhash. Mktbh Almtnby. Aldmam.

[5] Atfaqyh Hqwq Alashkhas Dwy Ala'aqh. (2006). (Altqryr Alkhtamy Lljnh Almkhssh Lwd' Atfaqyh Dwlyh Shamlh Wmtkamlh Lhmayh Wt'zyz Hqwq Alashkhas Dwy Ale'aqh Wkramthm).

[6] Brghman, Lwra W Trwml, Styfan. (2010). "Wthyqt Alershad Waltwjyh Walast'mal Alkfw' Llalyat Aldwlyh Lmraqbh Wrsd Hqwq Alashkhas Dwy Ale'aqh Whmaytha". Althalf Aldwly Lle'aqh. Jnyf. S (8-97).

[7] Albblawy, Ayhab. (2013). Tw'yt Almjtm' Bale'aqh. Altb'h Alsadsh. Dar Alzhra' Lltba'h Walnshr. Alryad.

[8] Aldhashmh, Khtam. (2011). "Alhqwq Alajtma'yh Alkhash Bdwy Ala'aqh Fy Dw' Alfqh Alaslamy Walqanwn Alardny". Rsalt Majstyr Ghyr Mnshwrh. Klyt Alshry'h Waldrasat Alaslamyh: Jam't Alyrmwk. Alardn. S 1-216. 
[9] Drar, Mnyh. (2014). "Mstwa M'erfh Mdyry Wm'lmy Almdars Alty Ytwfr Fyha Ghrf Almsadr Bhqwq Altlbh Dwy Ala'aqh". Rsalt Majstyr Ghyr Mnshwrh. Aljam'eh Alardnyh. 'man. Alardn. S (1-108).

[10] Dwbkat, Fkhry؛ Mghrby, 'bdalrhmn. (2014). "Mda Tdmyn Hqwq Alashkhas Dwy Ala'aqh Fy Mnhaj Altrbyh Almdnyh Alflstyny Fy Almrhlh Alasasyh Aldnya (Mrhlh Althy'eh Mn Alsf 1-4)". Mjlt Jam't Alqds Almftwhh Llabhath Waldrasat Altrbwyh Walnfsyh: 2(6): 173-202.

[11] Abw Ghryb, 'aydh. (2009). "Wrqh 'ml B'nwan: Hqwq Alashkhas Dwy Ale'aqh 'la Almstwa Aldwly Wal'rby". Alm'tmr Al'lmy Althany Lljm'yh Altrbwyh Lldrasat Alajtma'yh, Hqwq Alensan Wmnahj Aldrasat Alajtma'yh, Fy Alftrh Mn 26-27 Ywlyh 2009, Msr, Aljm'yh Altrbwyh Lldrasat Alajtma'yh- Jam't 'yn Shms, S (252-279).

[12] Alhmd, Nayf: Alhsn, Hsyn : Alshr'h, Nasr. (2017). "Mstwa Alw'y Bhqwq Alashkhas Dwy Ala'aqh Lda Talbat Klyt Erbd Aljam'yh". Mjlt M'th Llbhwth Waldrasat: Slslt Al'lwm Alansanyh Walajtma'yh: Alardn, 32(4): 183- 210.

[13] Jabr, Sabr. (2015). "Ale'lam Wdwrh Fy Nshr Alw'y Bqdaya Hqwq Alensan". Wrqh Mqdmh Llm'tmr Alra'd Lmthdy Ala'aqh Bjam't Alfywm. Msr. (Alukah.Net/Social/0/105518/ / ).

[14] Alkhza'y, Hsyn: Amarh, Th. (2009). Altshry'at Alajtma'yh Whqwq Alensan. 'man. Dar Yafa Al'Imyh.

[15] Alkhtyb, Jmal. (2013). Ass Altrbyh Alkhash. Mktbh Almtnb'. Aldmam. Altb'h Alawla.

[16] Mrzwq, Wfa'. (2010). Hmayt Hqwq Altfl Fy Zl Alatfaqyat Aldwlyh, Byrwt. Mnshwrat Alhlby Alhqwqyh.

[17] Alqasmy, Jmylh. (2017). "Adka' Alw'y Bhqwq Alashkhas Dwy Ale'aqh", Mqal Bmwq' Mjlt Almnal Alalktrwny: https://almanalmagazine.com

[18] Alqmsh, Mstfa ؛ Als'adh, Najy. (2008). Qdaya Wtwjhat Hdythh Fy Altrbyh Alkhas. Dar Almsyrh Llnshr Waltwzy'. Altb'h Alawla.

[19] Shhath, Hsn \&Walnjar, Zynb. (2003). M'jm Almstlhat Altrbwyh Walnfsyh, Alqahrh, Aldar Almsryh Allbnanyh.

[20] Alshly, Slma. (2018). "W'y Awlya' Amwr Dwy Ale'aqh Alfkryh Fy M'ahd Wbramj Altrbyh Alfkryh Bhqwq Abna'hm". Rsalt Majstyr Ghyr Mnshwrh. Klyt Altrbyh. Jam't Almlk S'ewd. S 1-135.

[21] Shtwry, Slah. (2012). "R'ayh Wtahyl Dwy Ale'aqh Fy Zl Altshry'at Walqwanyn Almsryh". Mwq' Atfal Alkhlyj Dwy Alahtyajat Alkhash. Http://Www.Gulfkids.Com/Vb/Showthread.Php?T=2525

[22] Alswylm, Alshrfat. (2015). "Drash Thlylyh Llatfaqyh Aldwlyh Lhqwq Alashkhas Dwy Ala'aqh Mqarnh Bahkam Alshry'h Alaslamyh". Alakadymyh Lldrasat Alajtma'yh Walansanyh: Tsdr 'n Jam't Hsybh Bn 'ly Balshlf Aljza'r. 7(2): 3-15.

[23] Zwral, 'bdalslam. (2015). "Hqwq Alashkhas Dwy Ala'aqh Fy Atar Atfaqyh Alamm Almthdh", Mjlt Jbl Hqwq Alansan, Mrkz Jbl Albhth Al'lmy: Aljza'r. 6(7): 155-170. 